\title{
Does a brief mindfulness induction change delay discounting in individuals with high levels of obsessive-compulsive symptoms?
}

Cierra B. Edwards

West Virginia University, cgbrooks@mix.wvu.edu

Follow this and additional works at: https://researchrepository.wvu.edu/etd

Part of the Behavior and Behavior Mechanisms Commons, Mental Disorders Commons, and the Psychological Phenomena and Processes Commons

\section{Recommended Citation}

Edwards, Cierra B., "Does a brief mindfulness induction change delay discounting in individuals with high levels of obsessive-compulsive symptoms?" (2021). Graduate Theses, Dissertations, and Problem Reports. 8343.

https://researchrepository.wvu.edu/etd/8343

This Dissertation is protected by copyright and/or related rights. It has been brought to you by the The Research Repository @ WVU with permission from the rights-holder(s). You are free to use this Dissertation in any way that is permitted by the copyright and related rights legislation that applies to your use. For other uses you must obtain permission from the rights-holder(s) directly, unless additional rights are indicated by a Creative Commons license in the record and/ or on the work itself. This Dissertation has been accepted for inclusion in WVU Graduate Theses, Dissertations, and Problem Reports collection by an authorized administrator of The Research Repository @ WVU.

For more information, please contact researchrepository@mail.wvu.edu. 
Does a brief mindfulness induction change delay discounting in individuals with high levels of obsessive-compulsive symptoms?

Cierra B. Edwards

Follow this and additional works at: https://researchrepository.wvu.edu/etd

Part of the Behavior and Behavior Mechanisms Commons, Mental Disorders Commons, and the Psychological Phenomena and Processes Commons 
Does a brief mindfulness induction change delay discounting in individuals with high levels of obsessive-compulsive symptoms?

Cierra B. Edwards

Dissertation submitted to the Eberly College of Arts and Sciences at West Virginia University in partial fulfillment of the requirements for the degree of Doctor of Philosophy in Clinical Psychology

\author{
Shari Steinman, Ph.D. (Chair) \\ Natalie Shook, Ph.D. \\ Kris Martens, Ph.D. \\ Jane Ruseski, Ph.D. \\ Department of Psychology \\ Morgantown, WV 2021
}

Keywords: OCD, Delay Discounting, Mindfulness

Copyright 2021 Cierra B. Edwards 


\begin{abstract}
Does a brief mindfulness induction change delay discounting in individuals with high levels of obsessive-compulsive symptoms?
\end{abstract}

Cierra Edwards

Obsessive-compulsive disorder (OCD) is a mental illness characterized by obsessions and compulsions that cause significant distress and/or functional impairment. Delay discounting, the decline in value of a reward with the delay of its receipt, is linked to a range of maladaptive behaviors and mental disorders. Increased delay discounting is related to obsessive-compulsive disorder (OCD), reflecting that compulsive behaviors that aim to counteract obsessive thoughts are viewed as uncontrollable by the sufferer. We aimed to experimentally reduce delay discounting in individuals with high levels of obsessive-compulsive symptoms through a brief mindfulness induction. Eligible participants were randomly assigned to receive either a mindfulness or thought wandering induction before completing counter-balanced monetary and handwashing delay discounting tasks and questionnaires. In Study 1, participants were adults ( $N$ $=84$ ) who completed the study in-person pre-pandemic response from November 2019 through March 2020 in the US. In Study 2, adult participants $(N=79)$ completed the study online due to the pandemic from June to November 2020. The mindfulness condition did not exhibit increased state mindfulness in either sample. There were no differences in delay discounting between participants who received the mindfulness condition and those who completed the thought wandering condition in either sample. There was an order effect for the first sample such that participants who completed the handwashing delay discounting task first had increased delay discounting/more impulsive choices on that measure. We found significant relations between this handwashing delay discounting task and related obsessive-compulsive symptoms. Monetary delay discounting was not associated with OCD symptoms. Findings suggest that presentation of threat-relevant information may lead to steeper discounting. Additionally, our results provide further evidence for differential delay discounting across reward types. Our study highlights the need for threat-relevant and/or symptom specific tasks in future studies examining delay discounting in OCD. 


\section{Acknowledgements}

During the dissertation process, I have received phenomenal support and assistance from my doctoral program and a number of people in my life. This research was funded through the WVU Department of Psychology Graduate Research Fund Award and the Eberly College of Arts and Sciences Doctoral Research Award. I am grateful to Dr. Shari Steinman, my advisor and dissertation chair, for her compassion, mentorship, and lived professional values in her work with me and each of her trainees. I offer my thanks to my committee members, Drs. Kris Martens, Natalie Shook, and Jane Ruseski, for their helpful input on this project and for being excellent role models in their scientific-mindedness and collegial approach to academia. I express my gratitude to the faculty of the Clinical Training Committee at WVU for everything they have done collectively and individually to help me develop my clinical acumen and support me in completing my training, particularly Dr. Amy Fiske for facilitating positive behavioral change. I would also like to thank mentors from my internship program for their faith in me and guidance in my professional development, especially Drs. Jessica Alldredge, Jacqueline Allen, David Baum, Kristin Rodzinka, and Joshua Wilson. I am grateful to the Cognition Anxiety and Treatment lab and the undergraduate research assistants who assisted with data collection, particularly Julean Bender, Ilona Carenbauer, Madison McCormick, and Madeline Price. Many thanks to my peers, friends, and family for all of their support. A special shout out to Celine Brooks and Richard Cui for encouraging me throughout my graduate training and for providing an endless supply of coffee and witticisms. Finally, I am especially grateful to my partner, Steven Edwards, and our daughter, Holly, for being my reason and for their enduring love. 


\section{Table of Contents}

Does a brief mindfulness induction change delay discounting in individuals with high levels of obsessive-compulsive symptoms?

OCD Overview

OCD Epidemiology and Assessment

OCD Etiology and Maintenance

OCD vs. OCPD

Delay Discounting

Delay Discounting and Mental Health

Delay Discounting and OCD

Changing Delay Discounting

OCD, Delay Discounting, and Mindfulness

Current Study

Study 1

Method

Participants

Measures

$\begin{array}{ll}\text { Preselection } & 15\end{array}$

$\begin{array}{ll}\text { In-session Measures } & 17\end{array}$

Mindfulness and Thought Wandering Inductions 20

Delay Discounting Tasks $\quad 21$

$\begin{array}{ll}\text { Procedure } & 23\end{array}$

Results

Descriptive Statistics

Induction Effectiveness

Delay Discounting Differences $\quad 25$

Discussion

Exploratory Analyses

Study 2

Method

Participants

30

Measures

Procedure

Results

Descriptive Statistics

Induction Effectiveness

Delay Discounting Differences

Exploratory Analyses 
Does a brief mindfulness induction change delay discounting in individuals with high levels of

$$
\text { obsessive-compulsive symptoms? }
$$

\section{OCD Overview}

OCD is characterized by obsessions and compulsions that cause significant distress and/or impairment in functioning. According to criteria from the Diagnostic and Statistical Manual of Mental Disorders Fifth Edition (DSM-5; American Psychiatric Association, 2013), obsessions are recurrent unwanted thoughts, images, or doubts that are intrusive, distressing, and anxiety-provoking. Common obsessional themes include intrusive thoughts related to contamination, sex, scrupulosity, inflated responsibility, and harming others (Clark \& Radomsky, 2014). Obsessions are experienced as ego-dystonic; they are dissonant with how one views one's self. Compulsions are repetitive behaviors a person utilizes to resist, counteract, or neutralize obsessions or anxiety (Leckman et al., 1997). Some common types of compulsions are washing, cleaning, checking, repeating, and mental review (Abramowitz et al., 2009).

Presentations of OCD are manifold and limited only by the individual's personal concerns and experiences (Abramowitz et al., 2018). The four most common manifestations of OCD are contamination, checking/responsibility, unacceptable thoughts, and symmetry/just right (Abramowitz et al., 2010). Each of these presentations is still fundamentally "OCD” because of the distressing combination of obsessions and compulsions, while the content of the thoughts and rituals is idiosyncratic to the person. Cultural stereotypes of OCD perpetuate mental health stigma and the misunderstanding that OCD is just a label for people who prefer to be neat and tidy or are afraid of germs (Williams et al., 2020). The reality is that this disorder is highly heterogeneous and compulsions are experienced as nearly uncontrollable behavior aimed at reducing the distress from obsessions. 


\section{OCD Epidemiology and Assessment}

Identifying who is at risk and the various presentations of OCD is critical to understanding the nature of this highly debilitating illness. According to older estimates from the DSM-5, the prevalence rate of OCD was approximately $2.3 \%$ for the lifetime and $1.2 \%$ for a 12 month period (American Psychiatric Association, 2013). OCD occurs in males and females at about the same rate (American Psychiatric Association, 2013). More recent estimates from a meta-analysis of epidemiological studies of OCD rates worldwide suggest a lifetime prevalence rate of $1.5 \%$ in women and $1.0 \%$ in men (Fawcett et al., 2020). The mean age of OCD onset is 19.5 years, but symptoms often appear in early adolescence (American Psychiatric Association, 2013). Females are affected at a slightly higher rate in adulthood compared to males, while males develop the disorder at a higher rate in childhood (American Psychiatric Association, 2013). Genetic influences for OCD range from 45-65\% in children and $27-47 \%$ in adults (Grootheest et al., 2005). OCD has a concordance rate of 0.57 for monozygotic and 0.22 for dizygotic twins, making it one of the more hereditary mental illnesses (Pauls, 2010).

Comorbidities with other mental disorders and challenges with differential diagnosis further complicate our understanding of OCD. Commonly co-occurring mental disorders include tic disorder, anxiety and depressive disorders, obsessive-compulsive personality disorder (OCPD), and substance use disorders (Ruscio et al., 2010). Differential diagnoses include these comorbidities, eating disorders, and psychotic disorders (Davis et al., 2019). Given the high level of comorbidities and overlap with disorders with similar features, best clinical practice for diagnosing and assessing OCD symptoms is through a structured clinical interview and/or validated symptom-based measures (Davis et al., 2019). OCD diagnosis is most reliably established through a validated structured clinical interview (First \& Williams, 2016; Tolin et al., 
2018). Symptom measures like the Obsessive Compulsive Inventory-Revised (OCI-R; Foa et al., 2002) are typically used to gauge OCD severity.

\section{OCD Etiology and Maintenance}

From a neuroanatomical perspective, abnormalities in the orbitofrontal cortex (OFC), anterior cingulate cortex (ACC), and striatum have been strongly implicated in OCD (Pauls et al., 2014). Individuals with OCD exhibit hyperactivity during rest in the cortico-basal-thalamocortical loop that includes the OFC, ACC, and the head of the caudate nucleus (Pauls et al., 2014). In terms of neurochemistry, serotonergic and dopaminergic neurotransmitter systems are among several that have been associated with the pathogenesis of OCD (Lissemore et al., 2021). Support for the serotonin hypothesis (i.e., implication of the serotonergic system in OCD presentation) has been drawn mainly from clinical trials demonstrating the efficacy of selective serotonin reuptake inhibitors (SSRIs) in the treatment of both adult and pediatric OCD (Sinopoli et al., 2017) Individuals with OCD have excessive baseline activity of excitatory glutamatergic neurons in the OFC (Wu et al., 2012). Serotonin inhibits these neurons. It is theorized that SSRI medications result in an increase of serotonin in the OFC, thus leading to a decline in OCD symptoms (Eddy et al., 2004). These neuroanatomical and neurochemical differences in individuals with OCD appear to result in deficits on neurobehavioral tasks. There is a consistent pattern of deficits in fronto-striatal executive functions, particularly impairments in utilization of organization strategies and decreased memory confidence (Pauls et al., 2014).

Psychological behavioral models posit that OCD is maintained through a cycle of negative reinforcement. When obsessional thoughts occur, compulsions function as an avoidance behavior. The compulsions allow the individual with OCD to temporarily avoid the horrific, feared outcomes associated with their obsessive thoughts. Thus, the disorder is maintained in the 
long-run through a cycle of negative reinforcement vis-à-vis operant conditioning (Antony et al., 2007). People with OCD choose the immediate reward of engaging in a compulsion and having reduced anxiety at the long-term expense of maintaining the disorder. OCD is not motivated by perfectionism as lay people often assume and is much more behavioral addiction like.

Following these theoretical models of OCD, many researchers think that increased delay discounting, a preference for more immediate rewards, may be a common feature across OCD presentations (Benatti et al., 2014). From this perspective, there is likely increased delay discounting in OCD because compulsions function as immediate reinforcers that reduce anxiety (Murphy et al., 2010). Other theories posit that OCD may be associated with decreased delay discounting via perfectionistic tendencies (Moulding \& Kyrios, 2006; Rhéaume et al., 1995; Skodol \& Oldham, 1996) or through excessive harm-avoidance (Hollander \& Wong, 1995; Potenza et al., 2009). However, these alternative explanations of the relation between delay discounting and OCD seem to equate compulsions in OCD with compulsivity as a personality trait and repetitive behaviors more broadly.

\section{OCD vs. OCPD}

Not all repetitive behaviors are compulsions because these behaviors do not always have the function of reducing anxiety in response to an obsession (Wheaton et al., 2010). For instance, people might spend several hours a day checking and responding to emails as part of their job or because they like having their inbox in order and responding to others in a timely manner. In the former case, the repetitive checking behavior is appropriate to the context; in the latter, it may be a personality trait that brings some amount of pleasure or satisfaction to the person. ${ }^{1}$ In both of

\footnotetext{
${ }^{1}$ These two functions are not mutually exclusive; but neither is maintained through negative reinforcement. One can spend significant time responding to emails as part of a job requirement and because they are overly conscientious, preoccupied with orderliness, or perfectionistic (or all of the above).
} 
these situations, the repetitive behavior does not function to reduce anxiety or distress as is the case in OCD.

When perfectionistic repetitive behavior occurs as part of one's identity and personality, it may be an indication of OCPD. Unlike OCD, OCPD is characterized by rigidity, perfectionism, excessive conscientiousness, devotion to work, and repetitive behaviors performed without underlying obsessions (American Psychiatric Association, 2013). Compulsivity in OCPD is a bit of a misnomer because the person does not feel "compelled" to perform the behavior; it is really a descriptor of the repetitive behavior rather than the underlying function of the behavior. The motivation for the repetitive behavior in OCPD is that the individual prefers to behave that way (Ansell et al., 2010).

In contrast, individuals with OCD perform compulsions to temporarily relieve their anxiety (Steketee, 2011). Choosing to engage in compulsions is immediately reinforcing for people with OCD because compulsions stave off uncomfortable feelings of anxiety and distress. This is not unlike the way those with a substance use disorder or a behavioral addiction take up their immediate reward of choice; the emotions underlying the choice are just different (e.g., thrill-seeking or avoidance of withdrawal symptoms instead of anxiety). Delay discounting offers a useful framework for understanding why someone with OCD might choose the more immediate reward of lessened anxiety by performing a compulsion over the long-term reward of less severe OCD symptoms and functional impairment.

\section{Delay Discounting}

Delay discounting refers to the decrease in the value of a reinforcer with delay to its receipt (MacKillop, 2013). It is a phenomenon that is present across species, reward types, and delays (Odum, 2011a). Immediately available rewards are considered better than later rewards, 
more probable rewards are better than less likely rewards, and larger rewards are generally better than smaller rewards. Choices are often in conflict, however, when decisions are made between less reward now or more later on. Delay discounting is an intertemporal type of decision-making that is characterized by a preference for more immediate, smaller rewards over larger, later rewards (Lattal, 2013; Madden \& Johnson, 2010).

Increased delay discounting means that there is a stronger preference for the immediate reward compared to average, while decreased discounting refers to a greater inclination toward the later reward. With delay discounting, the choice of the more immediate reinforcer is viewed as the impulsive choice, and the delayed outcome choice is seen as the self-controlled response (Solnick et al., 1980). Delay discounting tasks are intended to estimate preference for immediate versus delayed reward by presenting actual or hypothetical choices. In humans, delay discounting tasks typically involve presenting participants with various hypothetical monetary choices between smaller rewards available immediately and larger rewards provided later (Odum, 2011a). Delay discounting provides a framework for understanding decision-making and is essential to understanding intertemporal choice behavior and psychopathology in humans. In general, people weigh immediate rewards disproportionately in these delay discounting tasks, however, some populations discount much more or less steeply than others.

Whether delay discounting is a stable, personality-like trait or state-dependent is a matter of increasing interest to the field (Lempert et al., 2019). Delay discounting has traditionally been viewed as a trait variable because it appears to be an enduring response style with high test-retest reliability (Odum, 2011b). This view is further supported by the evidence that delay discounting on one outcome is positively correlated with the degree of discounting on other rewards (Green \& Myerson, 2010). Additionally, delay discounting is related to a number of personality and 
individual difference variables, including extraversion and neuroticism (Mahalingam et al., 2014). Nonetheless, there is relatively little research examining consistency of delay discounting across a wide variety of reward types. A recent review of the literature indicates that there is likely a combination of state (e.g., outcome type) and trait (e.g., heritability, consistency) influences on delay discounting (Odum et al., 2020). There may be differential delay discounting depending on the type of outcome. In fact, nonmonetary outcomes are generally more steeply discounted than monetary rewards (Estle et al., 2007; Odum et al., 2020). There is a critical need to better understand factors that lead to steeper discounting of nonmonetary outcomes to facilitate behavior change.

\section{Delay Discounting and Mental Health}

Differences in delay discounting task performance are found across a range of mental disorders. Increased delay discounting is consistently associated with impulse-control disorders, substance dependence, and behavioral addictions (MacKillop et al., 2011; Reynolds, 2006). Preliminary evidence suggests that there may be increased delay discounting in schizophrenia, bipolar disorder, and major depressive disorder (Ahn et al., 2011; Heerey et al., 2007; Pulcu et al., 2014). On the other hand, decreased delay discounting is associated with anorexia nervosa and more lethal suicide attempts in older adults (Dombrovski et al., 2011; Steinglass et al., 2012). Clearly, excessive self-control, like impulsivity, can lead to maladaptive behavior. Given the array of behaviors and disorders that it is associated with, delay discounting is increasingly seen as a trans-disease process and vulnerability factor (Bickel et al., 2012). One possible application is manipulating delay discounting as a transdiagnostic treatment target (Best et al., 2012; Stanger et al., 2012). 


\section{Delay Discounting and OCD}

The neurophysiology involved in OCD may contribute to increased impulsivity on delay discounting tasks. Several studies have noted dysfunctional reward circuitry via the mesolimbic pathway in OCD similar to that seen in substance dependence, supporting the notion that compulsions are a behavioral addiction (Figee et al., 2011; Pauls et al., 2014; Rădulescu \& Marra, 2017). Increased delay discounting is linked to this reward pathway (Sackett et al., 2019; Saddoris et al., 2015). Furthermore, the striato-thalamo-orbitofrontal circuit is involved in the compulsive nature of drug addiction and OCD (Adinoff, 2004; Voon \& Dalley, 2015).

Altogether, the neurological evidence supports compulsions as failures in behavioral control and cognitive flexibility.

Several studies have examined delay discounting task performance within the context of OCD (Grassi et al. 2015; Mavrogiorgou et al., 2018). All previous studies have found either a positive relation between increased discounting and OCD or no association. ${ }^{2}$ Four studies have examined differences in monetary delay discounting tasks (e.g., multiple time delays with titrated rewards) in samples comparing individuals diagnosed with OCD to healthy controls. Of these, two studies found increased delay discounting for the OCD condition (Mavrogiorgou et al., 2018; Sohn et al., 2014). The other two studies found no differences in monetary delay discounting between OCD and healthy controls, though interestingly, these researchers predicted reduced discounting in OCD (Pinto et al., 2014; Steinglass et al. 2017). Two correlational studies found no association between monetary delay discounting and obsessive-compulsive symptoms in unselected college student samples (Ong, et al., 2018; Weatherly, 2012).

\footnotetext{
${ }^{2}$ There is currently no published review of delay discounting in OCD. Dr. Steinman and I are preparing a manuscript to address this gap in the literature (Edwards \& Steinman, 2021).
} 
Only one study has examined delay discounting with a task related to obsessivecompulsive symptoms. Delay discounting related to contamination and washing symptoms was evaluated with hypothetical choices about delaying handwashing following an anxiety-provoking imaginal scenario (Ong et al., 2018). The novel procedure consisted of reading the scenario and making choices between receiving amounts of money (descending $\$ 99, \$ 97.50$, etc.) and washing hands immediately or receiving $\$ 100$ after a delay to handwashing (e.g., $1 \mathrm{~min}, 7 \mathrm{~min}$, 30 min; Ong et al., 2018). There were no significant differences in monetary discounting between participants with high and low handwashing symptomology. Participants with high handwashing had a non-significant trend ( $p=.068$; Cliff's $\delta=0.17)$ toward increased discounting compared to participants with low handwashing on the handwashing discounting task, reflecting that symptom specific discounting tasks may be a more appropriate measure of the relation between discounting and OCD. Nonetheless, findings were non-significant and should be interpreted with caution.

\section{Changing Delay Discounting}

Given the strong relation between delay discounting and various mental disorders, there is significant interest in modifying delay discounting and determining if changing delay discounting improves clinical outcomes (Lempert et al., 2019). In general, most of the experimental manipulations of delay discounting in humans are brief and intended to induce state changes in delay discounting. A recent meta-analysis of studies experimentally manipulating delay discounting indicates that there are several methods for momentarily reducing discounting (Rung \& Madden, 2018). Among these, affect and mortality priming manipulations have inconsistent effects, while construal and temporal priming have modest support (Rung \& Madden, 2018). Framing of time and reward outcomes significantly alters discounting, as do 
contextual changes and learning-based approaches (Rung \& Madden, 2018). Clinical techniques and strategies that can be incorporated into treatment, such as mindfulness and episodic future thinking, have modest effects on reducing delay discounting (Rung \& Madden, 2018).

\section{OCD, Delay Discounting, and Mindfulness}

When it comes to obsessive-compulsive symptoms and delay discounting, however, mindfulness-based manipulations are particularly intriguing. Briefly, mindfulness refers to paying attention to and being in the present moment without judgment (Siegel et al., 2009). Being mindful of obsessions means allowing intrusive thoughts to be there without resisting them through compulsions. Mindfulness-based interventions emphasize cultivating a willingness to experience the distress from obsessive thoughts without evaluating them or trying to understand them. The anxiety "fizzles out" when using mindfulness because emotions and cognitions are allowed to run their course without interference or negative reinforcement.

Of the types of experimental reductions of delay discounting used in the existing literature, only mindfulness has been found effective in alleviating OCD symptoms in the context of broader therapeutic treatment. Therapies that utilize mindfulness, such as acceptance and commitment therapy (ACT), have a growing evidence base for treating OCD (Grayson, 2013; Twohig et al., 2010). Mindfulness is frequently used alongside the gold-standard treatment for OCD, exposure and response prevention (ERP), because of its emphasis on observing and accepting intrusive thoughts (Grayson, 2013). Mindfulness-based approaches may be especially helpful for coping with "sticky" obsessions that occur at a high frequency and are typically resisted through mental review (Twohig et al., 2006). Alternative approaches to reducing delay discounting, such as episodic future thinking and framing, may have the counterproductive effect of perpetuating uncertainty about choices and causing anxious distress. Given these factors, a 
mindfulness-based approach is likely the best available option for manipulating delay discounting in an OCD analogue.

In addition to its evidence basis in therapeutic treatment for OCD, even brief mindfulness training can influence individuals' attitudes and behavior in the moment (Brown et al., 2007). For instance, a 15 min mindfulness intervention resulted in reduced negativity bias and increased positive judgments (Kiken $\&$ Shook, 2011). In addition, one-session mindfulness training in naïve participants can reduce emotional arousal (Farb et al., 2007; Taylor et al., 2011). Further, mindfulness meditation trainings between 4-8 sessions have found reduced self-reported pain and somatic reactivity (Zeidan et al., 2011), decreased social anxiety and avoidance (Goldin et al., 2009), and reduced neural reactivity to stimuli invoking sadness (Farb et al., 2010). Mindfulness interventions have been shown to also increase working memory and executive functioning abilities (Morrison \& Jha, 2015). While the implications for brief mindfulness interventions for clinical outcomes is exciting, it is still unclear exactly how much mindfulness (e.g., number and length of sessions) is needed to induce transient, state changes and to achieve longer-lasting effects (Sayers et al., 2015).

To date, only two studies have attempted to experimentally manipulate delay discounting with mindfulness (Hendrickson \& Rasmussen, 2013; Morrison et al., 2014). In the first, Hendrickson and Rasmussen (2013) found that one 50 min mindful-eating training produced small but significant reductions in delay discounting of food-related outcomes, and the educational control condition had no difference in delay discounting. Additionally, there were no changes in monetary delay discounting (Hendrickson \& Rasmussen, 2013). On the other hand, Morrison et al. (2014) examined whether a one-session 60-90 min acceptance-based intervention specifically focusing on acceptance and values reduced monetary delay discounting compared to 
a waitlist-control. There was a large decrease in monetary delay discounting within the intervention condition, and there was a non-significant trend for less discounting in the experimental compared to the control condition (Morrison et al., 2014). Both of these studies used unselected samples of healthy undergraduate college students. These findings suggest that state mindfulness approaches may have a transient effect on delay discounting. Furthermore, delay discounting task measures may need to be tailored to the target problem as effects may be specific to the type of reward.

\section{Current Study}

The primary aim of the current study was to examine the efficacy of a mindfulness induction in reducing delay discounting in an OCD analogue sample. Participants with high obsessive-compulsive symptomology were randomly assigned to complete a brief mindfulness induction or a thought wandering control task. We anticipated that the mindfulness condition would result in less steep discounting of hypothetical delayed rewards compared to the control.

We evaluated whether delay discounting in obsessive-compulsive symptomology varied depending on the type of reward using a modified version of the task developed by Ong and colleagues (2018). We decided to include this novel task because similarly non-validated measures of delay discounting are often used in the literature (Odum et al., 2020). Furthermore, examining delay discounting with outcomes relevant to the population in question is one of the essential tasks for advancing this literature and addressing this trans-disease process in treatment. Following the induction, participants completed two delay discounting tasks presented in randomized order with hypothetical rewards related to 1) obsessive-compulsive symptomology and 2) money. We hypothesized that there would be steeper discounting of hypothetical rewards related to obsessive-compulsive symptomology relative to monetary rewards. We predicted that 
the mindfulness condition would lead to larger differences in discounting of obsessivecompulsive oriented rewards relative to monetary reinforcers.

Between-subjects changes can be difficult to detect in delay discounting tasks due to high variability within-persons (Madden et al., 2004; Odum, 2011b; Odum \& Baumann, 2010). Therefore, monetary delay discounting was examined within-subjects at two time-points: 1) preselection and 2) post-induction. Preselection was used to determine if potential participants met eligibility criteria and provided a "baseline" for some outcomes (i.e., obsessive-compulsive symptoms, monetary delay discounting). The preselection took place via an online survey, and the remainder of the study (e.g., induction, delay discounting tasks, self-reports) occurred as a single computerized in-person session pre-pandemic and online following pandemic related changes to data collection procedures. We anticipated that the mindfulness condition would exhibit less steep discounting over time. The obsessive-compulsive relevant discounting task is novel, and there is not an alternative, equivalent form of the measure (as was the case for the monetary delay discounting tasks). The benefit of including this measure at both times did not seem to outweigh the potential for testing effects. Therefore, obsessive-compulsive delay discounting was only assessed at post-induction.

We explored delay discounting differences between participants with high and low handwashing symptomology. We anticipated steeper discounting of threat-relevant rewards among individuals with higher symptoms. Finally, relations among delay discounting tasks and clinical variables (e.g., anxiety, trait mindfulness), and demographic variables (e.g., income, age) were explored at post-induction. Previous work in delay discounting has documented the significant impact that psychosocial variables can have on delay discounting (Odum \& Baumann, 2010; Peters \& Buchel, 2011). We hypothesized that greater obsessive-compulsive 
symptoms, anxiety, and self-reported impulsiveness, would be associated with increased monetary and obsessive-compulsive delay discounting. We expected that higher trait mindfulness and deeper consideration of future consequences would be related to decreased delay discounting across tasks. We did not include measures of IQ or working memory because we did not anticipate much variability in these outcomes as we intended to recruit a sample of primarily undergraduate students. Additionally, the relation between these outcomes and delay discounting is firmly established in the literature while there is less known about the other clinical variables we included in the design.

We examined whether it was possible to reduce delay discounting with a brief mindfulness induction in two samples with high obsessive-compulsive symptoms. We acknowledge that our study was intended to be exploratory in nature. Initially, collecting an adequate sample size to examine our hypotheses seemed feasible. Due to the global COVID-19 pandemic, in-person data collection (November 2019 - March 2020) was paused and the study session was later administered in an entirely online format (June - November 2020). Given this historical event and change in methodology, we present the findings as two separate studies with a summative discussion and conclusions at the end.

\section{Study 1}

The purpose of this study was to examine the efficacy of a brief mindfulness induction in reducing delay discounting in an OCD analogue sample collected in person in a laboratory setting. 


\section{Method}

\section{Participants}

Participants were 84 adults aged 18 to $36(M=20.88, S D=3.57)$ recruited from the West Virginia University psychology department selection pool and the community. ${ }^{3}$ Most participants $(n=63), 75.0 \%$, reported identifying as female. Ethnicity was reported as predominately non-Latinx $(n=73), 86.9 \%$. Participant race was reported as $77.4 \%$ White $(n=$ 65), 3.6\% Black $(n=3), 7.1 \%$ Asian $(n=6), 3.6 \%$ Middle Eastern/North African $(n=3), 1.2 \%$ Native American/American Indian/Alaska Native/Indigenous White $(n=1)$, and $7.1 \%$ Multiracial $(n=6)$. Median income was between $\$ 40,000$ to $\$ 49,999$, and median level of education was some college. A majority of participants $(n=43), 51.2 \%$, identified as being single.

\section{Measures}

\section{Preselection measures}

Participants completed the OCI-R, the Dimensional Obsessive Compulsive Scale (DOCS; Abramowitz et al., 2010), and a monetary measure of delay discounting to evaluate eligibility and preselection, "baseline" levels of obsessive-compulsive symptoms and delay discounting. A brief demographic questionnaire was used to characterize the sample and screen for exclusion criteria.

The OCI-R is a multidimensional 18-item Likert-type scale that is designed to measure the degree of obsessive-compulsive symptoms in the past month with five response options ranging from not at all to extremely (Foa et al., 2002). There are six subscales: washing, checking, obsessions, mental neutralizing, ordering, and hoarding. The OCI-R has strong

\footnotetext{
${ }^{3}$ Four potential participants were excluded from data analysis in this sample for having OCI-R scores less than 9 at the start of the study session.
} 
psychometric properties, including high internal consistency, test-retest reliability, validity, and sensitivity to treatment change (Abramowitz et al., 2005; Foa et al., 2002). The OCI-R was used to screen for the presence of obsessive-compulsive symptoms and to determine whether eligibility criteria are still met at the outset of the study session. See Appendix A.

Clinical samples report a high degree of symptoms on the OCI-R $(M=28.01, S D=$ 13.53), and this measure is sensitive at detecting the presence of OCD with scores at or above 21 indicating likely OCD (Foa et al., 2002). Some recommend lower cutoff scores for distinguishing probable OCD on the OCI-R, such as a score of 14 or above (Abramowitz \& Deacon, 2006). Scores of 15 or above on the OCI-R are within $1 S D$ of the mean score of a clinical OCD sample (Foa et al., 2002). Using this cutoff score for the OCI-R ensured that participants reported a significant level of obsessive-compulsive symptoms. To collect a symptomatic but not formally diagnosed sample, potential participants who scored within $1 S D$ of the clinical mean on the OCI-R, a score of 15 or greater, were invited to participate in the study. Only participants scoring a 9 or higher on the OCI-R (within 1.5 SD of the clinical mean) at the start of the in study session were included in the analyses to allow for day to day fluctuations in symptoms.

The DOCS is a multidimensional measure of obsessive-compulsive symptoms. The DOCS contains 20-items assessed with Likert-type statements across the following four categories: contamination, responsibility, unacceptable thoughts, and symmetry (Abramowitz et al., 2010). Each category has 5-items assessing the severity of time spent on obsessions and compulsions, avoidance, distress, functional impairment, and control (Abramowitz et al., 2010). Scores for the total and subscales are reached by summing the responses to individual items, with higher scores indicating greater symptom severity. The DOCS has good psychometric properties, including high internal consistency, test-retest reliability, construct validity, and diagnostic and 
treatment change sensitivity (Abramowitz et al., 2010; Melli et al., 2015). The subscales of the DOCS correlate strongly with the corresponding subscales of the OCI-R (e.g., contamination on the DOCS and washing on the OCI-R). The DOCS was used to examine preselection and postinduction levels of obsessive-compulsive symptoms. We included the DOCS in addition to the OCI-R to determine if there were changes in obsessive-compulsive symptoms following the induction. See Appendix B.

The 21-item Monetary Choice Questionnaire (MCQ-21; adapted from Kirby \& Marakovic, 1996) is a randomized-choice delay discounting task. Participants choose between small, immediately available monetary rewards $(\$ 15-\$ 83)$ or larger, later amounts $(\$ 20-\$ 85)$ across 21 trials with differing temporal delays ranging from 10 days from now to 70 days from now. Choices were converted to $k$ values, a discounting parameter with a hyperbolic function (Kaplan et al., 2016). Higher $k$ values reflect greater preference for the smaller, immediate reward or choice impulsivity. Given the large between-subjects differences in delay discounting that can crowd out manipulation effects, we included the MCQ-21 to establish baseline discount rates for each participant prior to the study. See Appendix C.

\section{In-session measures}

Participants completed the OCI-R at the beginning of the session to determine if eligibility criteria were still met. Following the induction and delay discounting tasks, a battery of self-report scales were completed. The DOCS was included in the in-session battery (in addition to preselection) to provide post-induction levels of obsessive-compulsive symptoms. Participants completed additional questionnaires during the study session as follows:

The Mindful Attention Awareness Scale - State (MAAS-S; Brown \& Ryan, 2003) is a brief measure of state mindfulness. The MAAS-S is a 5-item 7-point scale with response options 
ranging from not at all to very much. Items are reverse scored and averaged; higher scores reflect higher state mindfulness. The MAAS-S is a commonly used measure of state mindfulness and has good psychometric properties, including internal consistency, reliability, and construct validity (Brown \& Cordon, 2009). State mindfulness is commonly used to assess the impact of mindfulness trainings (Jordan et al., 2014; Lueke \& Gibson, 2016). Changes in state mindfulness on the MAAS-S predict a host of adaptive behaviors, such as more positive affect, better communication, and improved problem-solving and coping (Barnes et al., 2007; Brown \& Ryan, 2003; Ostafin \& Kassman, 2012; Weinstein et al., 2009). The MAAS-S was used as a manipulation check to determine if participants in the mindfulness condition had higher state mindfulness than those completing the thought wandering control. See Appendix D.

Two items were used to assess affect following the induction procedure (following Mata et al., 2013). These items ask participants how positive and how negative they are feeling in the moment on a 7-point Likert-type scale from not very to very. Additional information about the psychometric properties of these items was not available. This measure of state affect was included as a manipulation check for the induction to exclude the possibility that delay discounting task performance was due to a more positive mood. We did not anticipate changes in affect as a result of the manipulation. See Appendix E.

The Freiburg Mindfulness Inventory (FMI; Walach et al., 2006) is a 14-item measure of trait mindfulness. The 14 -item version is a short-form of the original 30 -item scale and is intended for use in more general samples (Buchheld et al., 2001). Response options are on a 4point scale from rarely to almost always. Items are summed for a total score (only item 13 is reverse-scored) with higher scores reflecting higher trait mindfulness. The FMI has good reliability, internal consistency, and convergent validity (Baer et al., 2009). The FMI has items 
that address presence and attention to experiences and actions, acceptance, openness to experience, and insightfulness dimensions of mindfulness (Bergomi et al., 2013). The FMI was included to characterize the sample and for use in exploratory analyses. See Appendix F.

The Barratt Impulsiveness Scale 11 (BIS-11; Patton et al., 1995) is a self-report measure of behavioral and attitudinal indicators of impulsiveness. The BIS-11 has 30 items, and responses are rated on a 4-point Likert-type scale from rarely/never to almost always. The BIS11 measures three aspects of impulsivity: attentional/cognitive, motor, and planning. Scores are obtained by summing items for the total and three subscales (non-impulsive items are reversescored). The BIS-11 and earlier versions of the scale have a history of strong psychometric properties (Stanford et al., 2009). Impulsivity as measured by the BIS-11 is higher in OCD patients than in healthy controls (Benatti et al., 2014). In addition, the BIS-11 was associated with delay discounting and obsessive-compulsive symptoms in previous studies (Grassi et al., 2015; Sohn et al., 2014). In the current study, the BIS-11 was used to characterize the sample and in exploratory analyses. See Appendix G.

The Depression Anxiety Stress Scale Short Form (DASS-21; Lovibond \& Lovibond, 1995a) measures common symptoms of depression, anxiety, and stress as they have occurred over the past week with 7-items on a Likert-type scale. Symptoms are rated on a 4-point scale from did not apply to me at all to applied to me very much or most of the time. Ratings are added together for each subscale with higher scores indicating greater symptom severity. The DASS-21 has demonstrated good psychometric properties in clinical and non-clinical samples, such as high internal consistency, test-retest reliability, and convergent and discriminative validity (Antony et al., 1998; Lovibond \& Lovibond, 1995b; Sinclair et al., 2012). The DASS-21 was used to characterize the sample and in exploratory analyses. Relatively less is known about how 
depression, anxiety, and stress relate to delay discounting. Including the DASS-21 also adds to this emerging literature. See Appendix $\mathrm{H}$.

The Consideration of Future Consequences Scale (CFCS; Strathman et al., 1994) is a 12item Likert-type scale that assesses the extent to which people consider proximal versus distal factors in decision-making on a 5-point scale from extremely uncharacteristic of me to extremely characteristic of me. The CFCS is scored by adding responses together (items 3-5 and 9-12 are reverse-scored) with higher numbers indicating greater consideration of future consequences. The CFCS has good psychometric properties, including high internal consistency, test-retest reliability, and validity (Hevey et al., 2010; Joireman et al., 2008). Greater consideration of future consequences is weakly related to decreased delay discounting, reflecting less impulsivity (Teuscher \& Mitchell, 2011). The CFCS was used to characterize the sample and in exploratory analyses. See Appendix I.

A demographics questionnaire assessed basic demographic information about participants (age, sex, race, etc.). The demographics questionnaire was used to describe the sample, to determine if there are preexisting differences between groups, and to examine exploratory relations among demographic variables and delay discounting. See Appendix J.

\section{Mindfulness and Thought wandering Inductions}

The mindfulness induction consisted of a 9 min auditory clip that guided participants through a mindful breathing exercise (adapted from Kiken \& Shook, 2011, also see Arch \& Craske, 2006; Kabat-Zinn, 1990). This exercise aimed to induce a state of mindfulness by having participants focus on their breathing in a comfortable sitting position. Acceptance of thoughts without judgment was encouraged, and a focus on bringing one's attention to the present breath and accompanying sensations was emphasized. A brief induction was chosen because short 
mindfulness trainings of $15 \mathrm{~min}$ or less have been shown to be sufficient to increase state mindfulness (Arch \& Craske, 2006; Kiken \& Shook, 2011). In addition, a 5 min mindful breathing training reduced delay discounting in unselected undergraduates (Dixon et al., 2019). See Appendix K.

The thought wandering induction mirrored the task demands of the mindfulness induction (adapted from Kiken \& Shook, 2011). It was a 9 min audio file with instructions provided at the same intervals as the mindfulness induction. Rather than guiding participants to focus on the present moment, this induction instructed participants to allow their minds to wander freely. The thought wandering induction did not include the acceptance aspects found in the mindfulness exercise. Controls that closely match mindfulness exercises for task demands are commonly used in the literature and are thought to strengthen the quality of the study design (Schumer et al., 2018). See Appendix L.

\section{Discounting Tasks}

For both delay discounting tasks, $k$ values, the slope of the discount functions, were calculated for each participant. A $k$ value is a free parameter that describes the extent to which the value of something degrades with delay to its receipt (Odum, 2011a). We decided to examine differences in $k$ values because we did not expect to find a normal distribution of discount rates. The other primary approach to quantifying delay discounting, area under the curve (AUC), assumes a normal curve and may be less sensitive in detecting variance among steep discounters (Yoon et al., 2017).

The handwashing delay discounting task (HDDT) was adapted from the procedure developed by Ong and colleagues (2018) that is intended to measure the tradeoff between handwashing and receiving money. The original task consisted of an imaginal scenario designed 
to invoke anxiety related to contamination obsessions and titrated choices between receiving amounts of money (descending \$99, \$97.50, etc.) and washing hands immediately or receiving $\$ 100$ after a delay to handwashing (1 $\mathrm{min}, 7 \mathrm{~min}, 30 \mathrm{~min}, 3$ hours, 12 hours). Indifference points for each delay (the last immediate value chosen) yielded an indifference curve, and area under the curve was used to estimate discount rates (Ong et al., 2018). In our version, participants were prompted with the same imaginal scenario and responded to 51 individually presented randomized choices (modified from Senecal et al., 2013) between washing hands immediately with a smaller reward (immediate amount ranged from \$10 to \$34) and delaying washing hands after so many minutes (time delay ranged from 1 to 180 minutes) with a larger reward (later amount ranged $\$ 25$ to $\$ 35)$. A $k$ value was derived at each of the 51 items and an overall $k$ value computed. Modifying the task to a randomized-choice format was intended to mitigate the disadvantages associated with using titration procedures for delay discounting tasks (e.g., order and framing effects) and so that the HDDT would echo the format used in the monetary delay discounting tasks. The HDDT was used as the obsessive-compulsive relevant delay discounting measure. See Appendix M.

The 27-item Monetary Choice Questionnaire (MCQ-27; Kirby et al., 1999) is a randomized-choice monetary delay discounting task. Choices are made between smaller, immediate monetary rewards (\$11-\$80) and larger rewards (\$25-\$80) available later. Trials are presented individually with temporal delays ranging from 7 days to 179 days from now. For each participant, a $k$ value was calculated using the choices made during the task. Higher $k$ values indicate greater preference for the smaller, sooner reward. The MCQ-27 was included as the primary monetary delay discounting outcome. We examined the effect of condition as a repeated 
measure with $k$ values derived at preselection and post-induction from the MCQ-21 and MCQ-

27. See Appendix N.

Procedure

Participants were recruited from the university's participant pool and from the WVU community. Potential study participants completed the preselection questionnaires (OCI-R, DOCS, demographics) and MCQ-21. Adults who scored a 15 or higher on the OCI-R were invited to participate in the in-person study. The study session took place in a private, quiet room with a research assistant present to facilitate participant engagement. The research assistant sat across the room and did not closely observe participant responses. Following informed consent, obsessive-compulsive symptomology was confirmed with a baseline assessment on the OCI-R. Participants were randomly assigned to take part in the mindfulness or thought wandering condition. Participants listened to the induction using noise canceling headphones provided by the experimenter. Following the induction, participants completed a brief state mindfulness and affect check. Participants then did the obsessive-compulsive and monetary oriented delay discounting tasks, the HDDT and MCQ-27. These two tasks were counterbalanced (i.e., half of the participants in each group took the HDDT first and the other half started with the MCQ-27). Then, participants completed a battery of questionnaires (DOCS, BIS-11, DASS-21, FMI, CFCS) in randomized order, although, demographics were done last. The in-person study session took approximately 45-60 minutes, and participants were compensated with $\$ 10$ or extra credit.

\section{Results}

\section{Descriptive Statistics}

The data were plotted and descriptive statistics were examined for each variable in order to identify any potential problems, such as missingness, non-normal distributions, and outliers. 
There was minimal missingness, ranging from $0 \%-1.2 \%$, and no data was missing for the dependent variables. Given the low rate of missingness, we excluded cases pairwise. All measures approximated normality and data met statistical assumptions, except for the monetary delay discounting tasks. The MCQ-21 $($ skew $=1.99$, kurtosis $=4.01)$ and MCQ-27 $($ skew $=2.46$, kurtosis $=6.90)$ were right-skewed and leptokurtic. Both measures were log-transformed. Following transformation, the distribution of the MCQ-21 (skew = -.33, kurtosis = -.69) and MCQ-27 (skew $=-.54$, kurtosis $=-.12)$ were normal.

A series of t-tests were conducted to verify that the experimental mindfulness and control thought wandering conditions did not differ in terms of baseline OCD symptoms, monetary delay discounting rate, and basic demographic variables (i.e., age). Chi square tests were conducted to determine differences in the other demographic characteristics of the sample (i.e., gender, ethnicity, and race). Based on the principles underlying random assignment, no group differences were expected. The conditions did not differ in terms of baseline OCD symptoms, as measured by the OCI-R $(p=.765)$ and DOCS $(p=.594)$, or in preselection monetary delay discounting rate, as measured by the MCQ-21 $(p=.175)$. Conditions did not differ by age $(p=.595)$. Additionally, conditions did not differ in terms of ethnicity, race, gender, income, education, or relationship status (all $p \geq .100$ ). See Table 1 for descriptive statistics of baseline measures by condition.

\section{Induction Effectiveness}

The effectiveness of the induction was evaluated by comparing state mindfulness and affect between the mindfulness and control conditions with t-tests. There were no differences between the conditions in state mindfulness $(p=.757)$ or state negative affect $(p=.886)$. The conditions differed in state positive affect, $(t(82)=2.02, p=.047, d=.44)$. Participants in the 
mindfulness condition had more positive affect following the induction $(M=4.90, S D=1.20)$ than those in the thought wandering control $(M=4.32, S D=1.34)$.

\section{Delay Discounting Differences}

We assessed for differences in obsessive-compulsive and monetary delay discounting on the HDDT and MCQ-27 using a multivariate analysis of variances (MANOVA) test. Significant effects were explored with follow up analysis of variances (ANOVA) tests. In the MANOVA, the between-subjects factors were condition (mindfulness or thought wandering) and order (HDDT or MCQ-27 presented first). Pre-selection monetary discounting rate was included in the analysis as a covariate. ${ }^{4}$ There was no main effect for condition $(p=.453)$. There was not a significant interaction between condition and order $(p=.298)$. There was a statistically significant difference in discounting based on order, $F(2,78)=3.74, p=.028$; Wilk's $\Lambda=0.913$, $\mathrm{y}_{\mathrm{p}}{ }^{2}=.087$. Follow up ANOVAs indicated an effect on the HDDT, $\left(F(1,83)=6.08, p=.016, \mathrm{y}_{\mathrm{p}}^{2}\right.$ $=.071)$, but no effect for the MCQ-27, $\left(F(1,83)=2.75, p=.101, \mathrm{y}_{\mathrm{p}}^{2}=.034\right)$. Participants who completed the HDDT first exhibited a higher discount rate and made more impulsive choices on the HDDT $(M=.120, S D=.013)$ than those who took the MCQ-27 first $(M=.073, S D=.014)$. See Figure 1 for order effect on the HDDT.

\section{Exploratory Analyses}

\section{Washing}

We examined differences in delay discounting between individuals with high $(\geq 5, n=$ $25)$ vs. low $(\leq 4, n=59)$ Washing subscale scores on the OCI-R (using procedure in Ong et al., 2018). We used a MANOVA with three between-subjects factors: condition (mindfulness or

\footnotetext{
${ }^{4}$ Results were examined with the inclusion of preselection obsessive-compulsive symptoms as a covariate. Main results were then reexamined with state positive affect included as a covariate. There were no significant differences in findings, so we reported results without these covariates for simplicity.
} 
thought wandering), order (HDDT or MCQ-27 presented first), and Washing (high or low). Preselection monetary discounting rate was included in the analysis as a covariate. ${ }^{5}$ Significant effects were explored with follow-up ANOVAs. There was no main effect for condition $(p=$ $.498)$. There was a main effect for order $\left(F(2,74)=5.20, p=.008 ;\right.$ Wilk's $\left.\Lambda=0.877, \mathrm{y}_{\mathrm{p}}^{2}=.123\right)$, following the same pattern as in the main analysis. Follow-up ANOVAs indicated an order effect on the HDDT, $\left(F(1,75)=10.54, p=.002, \mathrm{y}_{\mathrm{p}}^{2}=.123\right)$, but not the MCQ-27 $(p=.274)$.

Participants who completed the HDDT first had higher discounting/were more impulsive on the $\operatorname{HDDT}(M=.138, S D=.013)$ than those who did the MCQ-27 first $(M=.076, S D=.014)$.

There was a main effect for Washing, $F(2,74)=10.22, p<.001$; Wilk's $\Lambda=0.784, \mathrm{y}_{\mathrm{p}}^{2}=$ .216. Participants with high Washing had higher discounting/were more impulsive on the HDDT, $F(1,75)=12.36, p=.001, \mathrm{y}_{\mathrm{p}}^{2}=.141(M=.140, S D=.016)$, than those with low Washing $(M=$ $.073, S D=.010)$. There was no effect of Washing on the MCQ-27 $(p=.146)$. There were no significant interaction effects for order and condition, order and Washing, and condition and Washing (all $p \geq .057$ ). There was not a significant interaction among order, condition, and Washing $(p=.131)$.

\section{Correlations}

To explore associations among outcome measures and clinical variables of interest, Pearson's bivariate correlations were conducted. Specifically, we examined the relations among monetary and handwashing delay discounting (MCQ-27 and HDDT), obsessive compulsive symptoms (DOCS), trait mindfulness (FMI), time perspective (CFCS), self-reported impulsivity (BIS-11), and state anxiety, depression, and stress (DASS-21). See Table 2 for correlations among all measures.

\footnotetext{
${ }^{5}$ Results were reexamined with inclusion of preselection obsessive-compulsive symptoms and state affect as covariates. There were no differences in findings, so the results are reported without these covariates.
} 
Monetary and obsessive-compulsive discounting had a small, positive association $(r=$ $.25, p=.025)$. The Contamination subscale of the DOCS was related to the HDDT $(r=.32, p=$ $.003)$ as was the Washing subscale of the OCI-R $(r=.42, p \leq .001)$. Monetary and obsessivecompulsive delay discounting were not related to any of the other variables of interest (all $p>$ .050). Obsessive-compulsive symptoms had small to moderate, positive associations with depression, anxiety, stress, and impulsivity. Depression, anxiety, and stress were moderately, positively correlated with one another. Trait mindfulness had small, negative relations with depression, anxiety, and stress. Greater future time perspective was weakly associated with anxiety and impulsivity. There was no relation between either delay discounting task and income or age $($ all $p>.05)$.

\section{Discussion}

The purpose of Study 1 was to examine the efficacy of a brief mindfulness induction in reducing delay discounting on monetary and handwashing delay discounting tasks. Study 1 took place in a single, in-person study session. We expected that the mindfulness condition would increase state mindfulness and have no impact on state affect. Our check of our manipulation revealed no differences in state mindfulness between conditions. It is possible that our induction was too brief to induce state mindfulness. The symptomatic nature of our sample may have made it more challenging to alter state mindfulness with a short induction. Individuals with high levels of OCD symptoms have lower levels of trait mindfulness (Crowe \& McKay, 2016). Future research should consider piloting longer mindfulness inductions to determine the appropriate length necessary to reliably increase state mindfulness in this population.

Somewhat surprisingly, we found that the mindfulness condition had higher state positive affect than the thought wandering control. Relatively brief mindfulness trainings have been 
found to reduce negative mood (Johnson et al., 2015; Zeidan et al., 2010). Short experimental mindfulness inductions lessen negative thoughts and are inconsistently linked with improved regulation of negative affect (Kiken \& Shook, 2014; Leyland et al., 2019). Additionally, we did not assess state mindfulness or affect prior to the induction. It is possible that there were preexisting differences between groups in their state experiences just prior to the induction.

It was hypothesized that participants in the mindfulness condition would have lower discount rates on the HDDT and MCQ-27 compared to the thought wandering control. Additionally, we expected reduced monetary discounting from pre-selection to post-induction for the mindfulness condition. We did not anticipate differences based on delay discounting task presentation order. The main hypotheses were not supported. There were no differences in discounting based on condition and no interaction between condition and order.

Unexpectedly, we found an effect for order such that those who completed the HDDT first had higher discount rates on this task. It seems likely that the vivid, threat-relevant HDDT instructions provoked state anxiety in this sample. Future studies incorporating the HDDT or similar threat-relevant stimuli should consider assessing state anxiety to examine potential impacts of the task. The extant literature suggests that there is increased delay discounting of threat-related rewards in anxious individuals (Miloyan et al., 2016; Rounds et al., 2007; Worthy et al., 2014; Xia et al., 2017; Zhao et al., 2015). It seems likely that this effect did not carry over to the MCQ-27 because this task was not threat-relevant like the HDDT for individuals with obsessive-compulsive symptoms.

The relevance of the outcomes used in delay discounting tasks to symptomology is supported in part by our exploratory analyses comparing participants with high and low Washing OCI-R scores. The order effect was more pronounced, and there was a main effect for Washing 
that indicated more impulsive choices on the HDDT for participants with high Washing. This is similar to previous work that found a nonsignificant trend for a positive relation between washing compulsions and preference for more immediate handwashing rewards (Ong et al., 2018). Exploratory correlations revealed only a weak relation between the HDDT and MCQ-27. In addition, there were positive relations between handwashing delay discounting and washing and contamination specific OCD symptoms. The findings from Study 1 support differential delay discounting that is specific to the reward and context rather than an overall pattern of impulsive responding in individuals with obsessive-compulsive symptoms. Other studies utilizing undiagnosed and/or unselected undergraduate samples have also found correlations between delay discounting and specific obsessive-compulsive symptoms with handwashing and monetary tasks (Ong et al., 2018; Weatherly, 2012). Samples comparing monetary delay discounting between diagnosed individuals and healthy controls found increased impulsivity in those with OCD (Mavrogiorgou et al., 2018; Sohn et al., 2014) or no differences between subjects (Pinto et al., 2014; Steinglass et al. 2017). These inconsistencies may be partially explained by the lack of threat-relevance of monetary rewards to OCD symptoms.

In the current study, there were no other significant associations with either delay discounting task. The lack of significant correlations with delay discounting may be due to the relatively low variability in discount rate and symptomology in this sample. Other study measures were generally related to one another in ways that would be expected.

Given our small effect sizes and lower than intended sample size from the halt to inperson data collection due to the pandemic, it is likely that this sample was under-powered. It is possible that the mindfulness condition may have induced higher state mindfulness and reduced delay discounting with sufficient power. However, this seems unlikely given the brevity of the 
mindfulness intervention. Overall, the findings from Study 1 implicate threat-relevant stimuli in impulsive choices and suggest that symptom-specific delay discounting paradigms may be the most useful in understanding intertemporal choice behavior among individuals with obsessivecompulsive symptoms.

\section{Study 2}

The aim of this study was to examine the efficacy of the brief mindfulness induction in reducing delay discounting in an OCD analogue sample collected online in a setting of the participant's choice. We anticipated that any effects found in Study 1 would replicate in this sample.

\section{Method}

\section{Participants}

Participants were 79 adults aged 18 to $44(M=22.89, S D=5.55)$ recruited online from the West Virginia University psychology department selection pool and the WVU community. ${ }^{6}$ A majority of participants $(n=59), 74.7 \%$, reported being female. Ethnicity was predominately non-Latinx $(n=74), 93.7 \%$. Participant race was reported as follows: $82.3 \%$ White $(n=65)$, 5.1\% Black $(n=4), 6.3 \%$ Asian $(n=5), 1.3 \%$ Middle Eastern/North African $(n=1), 1.3 \%$ Asian, Pacific Islander/Native Hawaiian, White $(n=1), 1.3 \%$ Native American/American Indian/Alaska Native/Indigenous White $(n=1)$, and 2.5\% Multiracial $(n=2)$. Median participant income was between $\$ 40,000$ to $\$ 49,999$, and median level of education was some college. Most participants $(n=36), 45.6 \%$, identified as being single.

\section{Measures}

The same set of measures included in Study 1 were used in Study 2.

\footnotetext{
${ }^{6}$ Four potential participants were excluded from data analysis in this sample for having OCI-R scores less than 9 at the start of the study session.
} 


\section{Procedure}

The same procedure used in Study 1 was generally used in Study 2. The primary difference was that the study session took place entirely online and there was no ongoing interaction with an experimenter during the study. Compliance with study procedures was less controlled in this sample. It is unclear to what degree participants were engaged with the induction and other study task demands. The online study session generally took 30-45 minutes. Exact time was not recorded. Participants were compensated with $\$ 10$ or extra credit.

\section{Results}

\section{Descriptive Statistics}

The data were plotted and examined to ensure statistical assumptions were met and to address any problems (e.g., missingness, outliers). Missingness was low and ranged from 0\% $1.3 \%$. No data was missing for the delay discounting tasks. Missing cases were excluded pairwise. As in Study 1, all measures approximated normality and data met statistical assumptions with the exception of the monetary delay discounting tasks. Similarly, the MCQ-21 $($ skew $=1.91$, kurtosis $=3.13)$ and MCQ-27 $($ skew $=3.15$, kurtosis $=11.09)$ were right-skewed and leptokurtic in this sample. Both measures were log-transformed, resulting in normal distributions for the MCQ-21 (skew = -.33, kurtosis = -.69) and MCQ-27 (skew = -.54, kurtosis $=-.12$ ). See Table 3 for descriptive statistics by condition on study measures.

As in Study 1, t-tests were used to determine whether there were differences between the mindfulness and control thought wandering conditions in terms of baseline OCD symptoms, monetary delay discounting rate, and age. Chi square tests were used to verify that there were not differences in the other demographic characteristics of the sample. Based on the principles underlying random assignment, no group differences were expected. Conditions did not differ in 
baseline OCD symptoms on the OCI-R $(p=.894)$ or DOCS $(p=.200)$. Additionally, there were no differences in baseline monetary delay discounting rate on the MCQ-21 $(p=.123)$ or in participant age $(p=.386)$. Conditions did not differ by ethnicity, race, gender, income, education, or relationship status (all $p \geq .152$ ).

\section{Induction Effectiveness}

As in Study 1, the effectiveness of the induction was evaluated with t-tests comparing state mindfulness and affect between the conditions. For state mindfulness and state positive and negative affect, there were no differences between the mindfulness condition and thought wandering control (all $p \geq .090)$.

\section{Delay Discounting Differences}

We assessed for differences in discounting using a MANOVA test with two betweensubjects factors: condition (mindfulness or thought wandering) and order (HDDT or MCQ-27 presented first). Pre-selection monetary discounting rate was included in the analysis as a covariate. ${ }^{7}$ There was no main effect for condition $(p=.851)$ or order $(p=.055)$, and there was not a significant interaction between condition and order $(p=.847)$.

\section{Exploratory Analyses}

\section{Washing}

As in Study 1, we examined differences in delay discounting between individuals with high $(\geq 5, n=40)$ and low $(\leq 4, n=38)$ Washing subscale scores on the OCI-R. We used a MANOVA with the same three between-subjects factors, condition, order, and Washing. Preinduction monetary delay discounting was controlled for as a covariate in the model. ${ }^{8}$ There was

\footnotetext{
${ }^{7}$ Results were also examined with preselection obsessive-compulsive symptoms included in the model as a covariate. There were no differences in the results, so we reported the findings without this covariate.

${ }^{8}$ As in Study 1, there were no changes in results when preselection obsessive-compulsive symptoms were included as a covariate and findings were reported without including this covariate.
} 
no effect for condition $(p=.942)$ or order $(p=.070)$. There was no effect for Washing $(p=.326)$. There were no significant interaction effects among order, condition, and Washing for this sample $($ all $p<.05)$.

\section{Correlations}

Pearson's bivariate correlations were conducted to examine the relations among monetary and handwashing delay discounting (MCQ-27 and HDDT), obsessive compulsive symptoms (DOCS), trait mindfulness (FMI), time perspective (CFCS), self-reported impulsivity (BIS-11), and state anxiety, depression, and stress (DASS-21). See Table 4 for correlations among all measures in this sample.

Monetary and obsessive-compulsive delay discounting were not related $(r=.12, p=$ .275). Monetary delay discounting was not related to any of the other variables of interest (all $p<$ .05). Obsessive-compulsive delay discounting was weakly associated with overall obsessivecompulsive symptoms on the DOCS $(r=.23, p=.043)$ and OCI-R $(r=.22, p=.047)$. In addition, the Contamination subscale of the DOCS was correlated with the HDDT $(r=.32, p=$ .004). However, the Washing subscale of the OCI-R was not related to the HDDT $(r=.17, p=$ .113). Obsessive-compulsive symptoms were moderately, positively related to depression, anxiety, and stress. Depression, anxiety, and stress were moderately, positively correlated with one another. Trait mindfulness had small, negative relations with obsessive-compulsive symptoms, depression, anxiety, and stress. Greater future time perspective was moderately, negatively associated with impulsivity. In addition, impulsivity had small, negative correlations with depression, anxiety, and stress. Finally, there were no significant correlations between either delay discounting outcome and income or age (all $p>.05$ ). 


\section{Differences between samples}

T-tests were used to examine differences between the in-person (Study 1) and online (Study 2) samples in means on study variables. Chi square tests were used to determine whether there were differences in demographic characteristics between the samples. The in-person sample had lower preselection obsessive-compulsive symptoms on the DOCS $(t(161)=-3.02, p$ $=.003, d=-.49)$, state negative affect $(t(161)=-2.23, p=.027, d=-.35)$, session OCI-R $(t(161)$ $=-2.62, p=.010, d=-.41)$, trait mindfulness $(t(161)=-2.86, p=.005, d=-.45)$, and consideration of future consequences $(t(161)=-6.77, p<.001, d=-1.06)$. Additionally, the inperson sample had higher self-reported impulsivity $(t(161)=4.77, p<.001, d=.76)$. The online sample had higher Contamination and Washing subscale symptoms, on the DOCS and OCI-R respectively, at preselection and during the study session (all $p<.05, d=.33-.73$ ). The online sample was older on average, $t(161)=2.76, p=.006, d=.43$, but there were no demographic differences in ethnicity, race, gender, income, education, or relationship status based on chi square tests (all $p>.05$ ). There were no differences in delay discounting between samples.

\section{Discussion}

The aim of Study 2 was to examine the efficacy of a brief mindfulness induction in reducing delay discounting on monetary and handwashing tasks in an online sample. Our hypotheses were the same as those in Study 1 with the additional expectation that we would replicate any effects found in the first sample. ${ }^{9}$ Similar to Study 1 , we did not find support for the mindfulness manipulation. Additionally, we did not replicate the effect for higher positive state affect in the mindfulness condition in this sample. Given the ineffectiveness of the mindfulness manipulation, it is unsurprising that our main analyses here produced null findings as they did in

\footnotetext{
${ }^{9}$ Study 1 data was not analyzed prior to data collection for Study 2.
} 
Study 1 . There were no differences in delay discounting on either task between the mindfulness and thought wandering conditions.

We did not find an order effect for the HDDT in this sample. This may be explained by changes in participant responses to the HDDT related to COVID-19 pandemic. The online sample exhibited less variability in handwashing delay discounting, with a greater concentration of responses at the extreme of always picking the immediate reinforcer of handwashing immediately and a lower amount of money. This is likely due to increased public consideration for and implementation of handwashing related to the pandemic (Hutchins et al., 2020).

We found a similar pattern of findings in the exploratory analyses with high and low Washing participants. There was no effect for condition or order and no interaction effects. Exploratory correlations did not reflect a relation between the two delay discounting tasks. This is in contrast to most delay discounting literature which generally shows a pattern of the same type of responding across contexts (e.g., more impulsivity on one task is usually indicative of that pattern with another reward; Odum et al., 2020). There was a weak relation between handwashing delay discounting and overall obsessive-compulsive symptoms. We found a moderate association between handwashing delay discounting and contamination specific OCD symptoms. These correlations between specific symptoms and discounting of related rewards is in line with our results in Study 1 and previous work examining delay discounting and OCD symptoms in undiagnosed individuals (Ong et al., 2018; Weatherly, 2012). There were no other significant correlations with either delay discounting measure; however, the remaining study measures were correlated in a manner consistent with convergent validity.

Our sample was likely under-powered to detect significant effects for the main hypotheses. Nonetheless, other factors such as the format and length of the induction may have 
played a larger role in the null results. Additionally, attention checks were not used and level of participant engagement was indeterminable. The relative importance of the order of task presentation to handwashing discount rate was not supported in this sample. Differences between the samples in Study 1 and 2 likely played a role in the impact of order on the delay discounting tasks. For example, the lack of an order effect on the HDDT in Study 2 may be due to this sample's relatively higher and less variable level of obsessive-compulsive symptoms. In addition, the overall frequency of handwashing behavior has increased due to the pandemic, and this history effect likely impacts people's hypothetical choices about handwashing in a situation that is now universally threat-relevant.

\section{General Discussion}

The purpose of the current study was to examine the efficacy of a brief mindfulness induction in producing lower delay discounting rates compared to a thought wandering control in participants with high levels of obsessive-compulsive symptoms. This aim was examined in two study samples due to the ongoing global pandemic. Study 1 data was collected in person, while Study 2 was completed online. Delay discounting was measured with an obsessive-compulsive symptom relevant task, the HDDT, and with a more traditional, monetary task, the MCQ-27. These two tasks were counterbalanced in presentation. Strengths include the use of an analogue sample rather than unselected undergraduate students ${ }^{10}$ and the inclusion of both OCD specific and monetary delay discounting tasks.

Our hypotheses did not differ for the two samples. We hypothesized that the mindfulness condition would have higher state mindfulness and no differences in affect immediately

\footnotetext{
${ }^{10}$ Analogue samples are considered relevant for understanding OCD given the dimensional nature of obsessivecompulsive symptoms and our approach of using the clinically derived cutoff on an accepted measure of OCD, as described in the methods, are more generalizable to clinical samples than comparisons between high and low scorers (Abramowitz et al., 2014).
} 
following the induction. There were no differences in state mindfulness between conditions in either sample, reflecting that the manipulation was ineffective. One explanation for this null finding is insufficient power to detect a significant effect. Our sample size in Study 1 was limited by changes to data collection and the pandemic response. We did not have sufficient power to detect a medium effect based on our preliminary power analysis (Faul et al., 2007). We collected approximately the same number of participants in Study 2 and were similarly limited in power. We chose not to combine the two samples in our data analysis given the differences in data collection procedures. ${ }^{11}$ Another explanation for the null finding for the main manipulation is that our mindfulness induction may have been too short in duration to induce state mindfulness in our sample. While there is evidence that short mindfulness trainings can produce concomitant changes in state mindfulness (Kiken \& Shook, 2011), it is not clear if such brief interventions are effective in individuals with obsessive-compulsive symptomology.

We anticipated that the mindfulness condition would have reduced delay discounting across time (i.e., from preselection to post-induction). There was no within-subjects interaction effect for time and condition on delay discounting in either sample. We expected that the mindfulness condition would result in lower delay discounting/less impulsivity than the thought wandering control condition. There was not a main effect for condition on delay discounting in either sample. Our main hypotheses were not supported. The null findings can be explained by the lack of induced state mindfulness in the mindfulness condition. If state mindfulness had been induced successfully, we may have found differences in delay discounting between conditions. The limited research examining mindfulness based strategies to reducing delay discounting has

\footnotetext{
${ }^{11}$ There was no effect of the manipulation on state mindfulness when analyses were ran with both samples combined. There was no main effect for condition or interaction between condition and order on delay discounting when the main analyses were conducted with all participants.
} 
shown promising effects (Scholten et al. 2019). It is unclear to what extent a state change in mindfulness might alter delay discounting in the moment. While delay discounting has typically been seen as a stable, trait-like characteristic, it can be highly state-dependent. Various manipulations have been used to experimentally reduce delay discounting in the moment (Rung \& Madden, 2018). Furthermore, the degree of discounting is at least partially differentiated by reward type supporting a state conceptualization of delay discounting. Nonmonetary rewards in particular are more steeply discounted (Odum et al., 2020).

No order effects were anticipated. Somewhat surprisingly, we found a main effect for order on obsessive-compulsive delay discounting in the first sample. Participants who completed the HDDT first had increased discounting on that task. This effect was not replicated in Study 2. One possible explanation for the order effect is that the HDDT increased participants' anxiety. Higher anxiety is linked to impulsivity on delay discounting tasks (Rounds et al., 2007; Worthy et al., 2014). In support of this rationale, our exploratory analysis comparing high and low Washing scorers found this order effect with a stronger effect in the first sample. The order effect may have been present in Study 1 and not Study 2 because of the more ambiguous nature of the HDDT pre-pandemic. Willingness to delay washing one's hands after the imaginal scenario presented in the HDDT would likely be universally lower across people given the public threat posed by COVID-19. In pandemic times, a mucous substance on one's hand in a public restroom is more threat-relevant to everyone, not just individuals with contamination fears and washing compulsions.

In addition, we anticipated that those with high Washing symptoms would have increased impulsivity on the HDDT. There was a significant, strong effect for Washing in Study 1 on the HDDT but not the MCQ-27, suggesting that the type of reward used in a delay discounting task 
impacts the level of delay discounting. There was no effect for Washing in Study 2. The salience of frequent handwashing and illness prevention fundamentally differed between the two samples because of the COVID-19 pandemic. Handwashing has been identified as a key preventive method for reducing transmission of viral illnesses, including COVID-19 (Haque, 2020). Since mid-March 2020, many Americans, especially those at greater risk, have increased handwashing behavior as one protective measure against contracting and spreading this virus (de Bruin \& Bennett, 2020; Islam et al., 2021). Given these historical changes, it is unsurprising that the Washing effect we found in Study 1 did not extend to the online sample. ${ }^{12}$

We explored relations among the delay discounting tasks, self-report on clinically relevant variables, and demographics. We anticipated moderate to strong associations between the tasks as individuals typically exhibit similar discount rates across reward types (Odum et al., 2020). Surprisingly, our delay discounting tasks were only weakly correlated in Study 1 and had no association in Study 2. This suggests that in these samples, the way a participant responded on one task was not necessarily associated with their response style on other task. Discount rate may be unrelated between these tasks because the reward type differs. The lack of a correlation between the HDDT and MCQ-27 points toward specificity of reward type being a significant determinant of delay discounting in individuals with high obsessive-compulsive symptoms. Correlational analyses revealed a general lack of significant associations between delay discounting and variables of interest. There was support for an association between obsessivecompulsive delay discounting and related symptoms in both studies. This is line with the only other study to include a delay discounting task with relevance to obsessive-compulsive

\footnotetext{
${ }^{12}$ Other clinical or demographic variables may have contributed to additional differences in delay discounting. We did not conduct exploratory analyses between community members and student participants because nearly all participants in both samples were students. These factors should be examined in future studies.
} 
contamination symptoms (Ong et al., 2018). Overall, our exploratory correlations did not support a significant relation between delay discounting and the other clinical variables.

While there is tentative support for increased delay discounting in individuals with OCD, the mechanism for this relation is not understood (Grassi et al., 2015). Theoretically, obsessivecompulsive symptoms may lead to increased delay discounting of threat-relevant rewards. Individuals with OCD choose the short-term anxiety relief at the expense of the long-term maintenance of their disorder. This framework is supported by the effectiveness of treatments targeting prevention of compulsions and developing corrective information about obsessional fears (Arch \& Abramowitz, 2015). The presumed causal nature of the relation between OCD and delay discounting suggests that the obsessions lead to compulsions which are done for short-term anxiety reductions. Future work should test the directionality of the relation between threatrelevant delay discounting (e.g., with the HDDT) and OCD.

\section{Limitations}

There are several key limitations to the current study. First, the study was under powered to detect small or medium-sized effects. A priori power analyses were conducted, and we aimed to collect enough participants to detect medium effects with a healthy buffer to allow for unusable data. The combination of small sample sizes due to the restrictions in data collection and the probability of a true small effect size may have contributed to null findings across our main hypotheses. Given our insufficient power, it cannot be determined if the mindfulness training would have otherwise produced comparatively higher state mindfulness compared to the control. Our subsequent hypotheses on delay discounting differences were predicated on the training condition inducing state mindfulness. Future research on experimental reductions of delay discounting in OCD analogues should consider utilizing larger sample sizes if possible. 
Second, the mindfulness training may have been too brief to produce an effect of state mindfulness even in a large sample of individuals with high levels of obsessive-compulsive symptoms. Much of the research examining brief mindfulness interventions have used unselected undergraduate participants (Brown \& Cordon, 2009). The optimal length of mindfulness training to produce state mindfulness in an OCD analogue is not known. Relatedly, whether mindfulness is the best clinical intervention for reducing delay discounting is unclear as manipulations utilizing episodic future thinking have more consistently shown effects (Scholten et al., 2019). Episodic future thinking was not selected as the manipulation in this study because individuals with OCD symptoms have pathological doubt and uncertainty (Aardema et al., 2009; Olson et al., 2015). It is possible that episodic future thinking or another intervention type may have reduced delay discounting in our study. Future research should address dosage-related questions of how much clinical intervention is necessary to alter delay discounting, how long is delay discounting impacted, and do changes in discounting lead to commensurate changes in clinical symptoms.

Third, restricting our sample to individuals with high levels of OCD symptoms may have unnecessarily constrained variability across measures. All of our participants had high levels of obsessive-compulsive symptoms. It is possible we may have detected an effect for our manipulation if we had included an unselected sample of healthy and highly symptomatic participants. Similarly, we did not select participants with high handwashing specific OCD symptoms. The HDDT would not have been a threat-relevant task for participants with low levels of contamination obsessions and compulsions. Additionally, the HDDT would have been perceived differently by participants in Study 2 due to concerns about COVID-19 risk and 
protective measures being taken by the public. The level of threat posed by the HDDT instructions was likely high across participants in the second sample for this reason.

Fourth, the HDDT is not a validated measure of delay discounting. As this research area is in its infancy, there are no validated measures of delay discounting specific to handwashing or OCD symptoms. The extent to which the HDDT represents contextual factors of OCD symptomology is questionable given the task's novelty and heterogeneity of this disorder. We modified the HDDT from Ong and colleagues work (2018) to have a similar structure to the MCQ-27. The anxiety-provoking nature of the HDDT was maintained. It is possible we would have found different effects if we had examined delay discounting at the limited time points used by Ong and colleagues (2018) rather than deriving $k$ values. This may be particularly true for our online sample given the brevity of the time points they examined. Some of the delays to handwashing in our modification (e.g., 180 minutes) may have seemed extraordinary during the pandemic. Nevertheless, our study provides additional support for this task's relevance to individuals with obsessive-compulsive symptoms. Future studies should examine delay discounting of other threat-relevant rewards for different manifestations of OCD, such as responsibility for harm, scrupulosity, postpartum, unacceptable thoughts and symmetry.

\section{Conclusions}

This research aimed to provide support for mindfulness as a means of reducing delay discounting in individuals with obsessive-compulsive symptomology. It was anticipated that a brief mindfulness training would result in increased state mindfulness with a concomitant decrease in delay discounting compared to a thought wandering control condition. Our hypotheses were not supported as the mindfulness condition did not induce state mindfulness. There was no evidence that our manipulation had an impact on delay discounting. Nevertheless, 
we unexpectedly found that the order of delay discounting task presentation influenced discount rate. The task relevant to obsessive-compulsive symptoms, the HDDT, appeared to result in increased discounting in Study 1, perhaps due to an increase in state anxiety. Exploratory analysis among participants with high handwashing symptoms in Study 1 provided additional support for this order effect. Correlational analysis generally did not support a relation between delay discounting and other variables of interest in either sample. Overall, our results suggest that the type of reward used in delay discounting tasks may be especially relevant to understanding intertemporal choice behavior in individuals with obsessive-compulsive symptoms. 


\section{References}

Aardema, F., O'Connor, K. P., Pélissier, M. C., \& Lavoie, M. E. (2009). The quantification of doubt in obsessive-compulsive disorder. International Journal of Cognitive Therapy, 2(2), 188-205. https://doi.org/10.1521/ijct.2009.2.2.188

Abramowitz, J. S., Blakey, S. M., Reuman, L., \& Buchholz, J. L. (2018). New directions in the cognitive-behavioral treatment of OCD: Theory, research, and practice. Behavior Therapy, 49(3), 311-322. https://doi.org/10.1016/j.beth.2017.09.002

Abramowitz, J. S., \& Deacon, B. J. (2006). Psychometric properties and construct validity of the Obsessive-Compulsive Inventory-Revised: Replication and extension with a clinical sample. Journal of Anxiety Disorders, 20(8), 1016-1035. https://doi.org/10.1016/j.janxdis.2006.03.001

Abramowitz, J. S., Deacon, B. J., Olatunji, B. O., Wheaton, M. G., Berman, N. C., Losardo, D., ... \& Björgvinsson, T. (2010). Assessment of obsessive-compulsive symptom dimensions: Development and evaluation of the Dimensional Obsessive-Compulsive Scale. Psychological assessment, 22(1), 180-198. https://doi.org/10.1037/a0018260

Abramowitz, J. S., Fabricant, L. E., Taylor, S., Deacon, B. J., McKay, D., \& Storch, E. A. (2014). The relevance of analogue studies for understanding obsessions and compulsions. Clinical Psychology Review, 34(3), 206-217. https://doi.org/10.1016/j.cpr.2014.01.004

Abramowitz, J. S., McKay, D., \& Taylor, S. (Eds.). (2011). Obsessive-compulsive disorder: Subtypes and spectrum conditions. Elsevier.

Abramowitz, J. S., Taylor, S., \& McKay, D. (2009). Obsessive-compulsive disorder. The Lancet, 374(9688), 491-499. https://doi.org/10.1016/S0140-6736(09)60240-3 
Abramowitz, J. S., Tolin, D. F., \& Diefenbach, G. J. (2005). Measuring change in OCD: Sensitivity of the Obsessive-Compulsive Inventory-Revised. Journal of Psychopathology and Behavioral Assessment, 27(4), 317-324. https://doi.org/10.1007/s10862-005-2411-y

Adinoff, B. (2004). Neurobiologic processes in drug reward and addiction. Harvard Review of Psychiatry, 12(6), 305-320. https://doi.org/10.1080/10673220490910844

Ahn, W. Y., Rass, O., Fridberg, D. J., Bishara, A. J., Forsyth, J. K., Breier, A., ... \& O'donnell, B. F. (2011). Temporal discounting of rewards in patients with bipolar disorder and schizophrenia. Journal of Abnormal Psychology, 120(4), 911-921. https://doi.org/10.1037/a0023333

American Psychiatric Association. (2013). Diagnostic and Statistical Manual of Mental Disorders. Washington, DC.

Ansell, E. B., Pinto, A., Crosby, R. D., Becker, D. F., Añez, L. M., Paris, M., \& Grilo, C. M. (2010). The prevalence and structure of obsessive-compulsive personality disorder in Hispanic psychiatric outpatients. Journal of Behavior Therapy and Experimental Psychiatry, 41(3), 275-281. https://doi.org/10.1016/j.jbtep.2010.02.005

Antony, M. M., Bieling, P. J., Cox, B. J., Enns, M. W., \& Swinson, R. P. (1998). Psychometric properties of the 42-item and 21-item versions of the Depression Anxiety Stress Scales in clinical groups and a community sample. Psychological Assessment, 10(2), 176-181. https://doi.org/10.1037/1040-3590.10.2.176

Antony, M. M., Purdon, C. E., \& Summerfeldt, L. J. (2007). Psychological treatment of obsessive-compulsive disorder: Fundamentals and beyond (1st ed.). Washington, DC: American Psychological Association.

Arch, J. J., \& Abramowitz, J. S. (2015). Exposure therapy for obsessive-compulsive disorder: 
An optimizing inhibitory learning approach. Journal of Obsessive-Compulsive and Related Disorders, 6, 174-182. https://doi.org/10.1016/j.jocrd.2014.12.002

Arch, J. J., \& Craske, M. G. (2006). Mechanisms of mindfulness: Emotion regulation following a focused breathing induction. Behaviour Research and Therapy, 44(12), 1849-1858. https://doi.org/10.1016/j.brat.2005.12.007

Baer, R. A., Walsh, E., \& Lykins, E. L. (2009). Assessment of mindfulness. In: Didonna F. (Ed.), Clinical handbook of mindfulness (pp. 153-168). Springer, New York, NY. https://doi.org/10.1007/978-0-387-09593-6_10

Barnes, S., Brown, K. W., Krusemark, E., Campbell, W. K., \& Rogge, R. D. (2007). The role of mindfulness in romantic relationship satisfaction and responses to relationship stress. Journal of Marital and Family Therapy, 33(4), 482-500. https://doi.org/10.1111/j.1752-0606.2007.00033.x

Benatti, B., Dell'Osso, B., Arici, C., Hollander, E., \& Altamura, A. C. (2014). Characterizing impulsivity profile in patients with obsessive-compulsive disorder. International Journal of Psychiatry in Clinical Practice, 18(3), 156-160.

https://doi.org/10.3109/13651501.2013.855792

Bergomi, C., Tschacher, W., \& Kupper, Z. (2013). The assessment of mindfulness with self report measures: Existing scales and open issues. Mindfulness, 4(3), 191-202. https://doi.org/10.1007/s12671-012-0110-9

Best, J. R., Theim, K. R., Gredysa, D. M., Stein, R. I., Welch, R. R., Saelens, B. E., ... \& Wilfley, D. E. (2012). Behavioral economic predictors of overweight children's weight loss. Journal of Consulting and Clinical Psychology, 80(6), 1086-1096. https://doi.org/10.1037/a0029827 
Bickel, W. K., Jarmolowicz, D. P., Mueller, E. T., Koffarnus, M. N., \& Gatchalian, K. M. (2012). Excessive discounting of delayed reinforcers as a trans-disease process contributing to addiction and other disease-related vulnerabilities: Emerging evidence. Pharmacology \& Therapeutics, 134(3), 287-297. https://doi.org/10.1016/j.pharmthera.2012.02.004

Brown, K. W., \& Cordon, S. (2009). Toward a phenomenology of mindfulness: Subjective experience and emotional correlates. In Didonna F. (Ed.), Clinical handbook of mindfulness (pp. 59-81). Springer, New York, NY. https://doi.org/10.1007/978-0-387-09593-6_5

Brown, K.W., \& Ryan, R.M. (2003). The benefits of being present: Mindfulness and its role in psychological well-being. Journal of Personality and Social Psychology, 84, 822-848. https://doi.org/10.1037/0022-3514.84.4.822

Brown, K. W., Ryan, R. M., \& Creswell, J. D. (2007). Mindfulness: Theoretical foundations and evidence for its salutary effects. Psychological Inquiry, 18(4), 211-237. https://doi.org/10.1080/10478400701598298

Buchheld, N., Grossman, P., \& Walach, H. (2001). Measuring mindfulness in insight meditation (vipassana) and meditation-based psychotherapy: The development of the Freiburg Mindfulness Inventory (FMI). Journal for Meditation and Meditation Research, 1, 1134.

Clark, D. A., \& Radomsky, A. S. (2014). Introduction: A global perspective on unwanted intrusive thoughts. Journal of Obsessive-Compulsive and Related Disorders, 3(3), 265268. https://doi.org/10.1016/j.jocrd.2014.02.001

Crowe, K., \& McKay, D. (2016). Mindfulness, obsessive-compulsive symptoms, and executive 
dysfunction. Cognitive Therapy and Research, 40(5), 627-644.

https://doi.org/10.1007/s10608-016-9777-x

Davis, M. L., McIngvale, E., Schneider, S. C., Goodman, W. K., \& Storch, E. A. (2019).

Obsessive-Compulsive and Related Disorders. In Segal D. (Ed.), Diagnostic

Interviewing (pp. 155-177). Springer, New York, NY.

https://doi.org/10.1007/978-1-4939-9127-3_7

de Bruin, W. B., \& Bennett, D. (2020). Relationships between initial COVID-19 risk perceptions and protective health behaviors: A national survey. American Journal of Preventive Medicine, 59(2), 157-167. https://doi.org/10.1016/j.amepre.2020.05.001

Denys, D., Zohar, J., \& Westenberg, H. G. (2004). The role of dopamine in obsessivecompulsive disorder: Preclinical and clinical evidence. Journal of Clinical Psychiatry, 65(Suppl 14), 11-17.

Dixon, M. R., Paliliunas, D., Belisle, J., Speelman, R. C., Gunnarsson, K. F., \& Shaffer, J. L. (2019). The effect of brief mindfulness training on momentary impulsivity. Journal of Contextual Behavioral Science, 11, 15-20. https://doi.org/10.1016/j.jcbs.2018.11.003

Dombrovski, A. Y., Szanto, K., Siegle, G. J., Wallace, M. L., Forman, S. D., Sahakian, B., ... \& Clark, L. (2011). Lethal forethought: Delayed reward discounting differentiates high-and low-lethality suicide attempts in old age. Biological Psychiatry, 70(2), 138-144. https://doi.org/10.1016/j.biopsych.2010.12.025

Eddy, K. T., Dutra, L., Bradley, R., \& Westen, D. (2004). A multidimensional meta-analysis of psychotherapy and pharmacotherapy for obsessive-compulsive disorder. Clinical Psychology Review, 24(8), 1011-1030. https://doi.org/10.1016/j.cpr.2004.08.004 
Epstein, L. H., Salvy, S. J., Carr, K. A., Dearing, K. K., \& Bickel, W. K. (2010). Food reinforcement, delay discounting and obesity. Physiology \& Behavior, 100(5), 438-445. https://doi.org/10.1016/j.physbeh.2010.04.029

Estle, S. J., Green, L., Myerson, J., \& Holt, D. D. (2007). Discounting of monetary and directly consumable rewards. Psychological Science, 18(1), 58-63. https://doi.org/10.1111/j.1467-9280.2007.01849.x

Farb, N. A. S., Anderson, A. K., Mayberg, H., Bean, J., McKeon, D., \& Segal, Z. V. (2010). Minding one's emotions: Mindfulness training alters the neural expression of sadness. Emotion, 10, 25-33. https://doi.org/10.1037/a0017151

Farb, N. A. S., Segal, Z. V., Mayberg, H., Bean, J., McKeon, D., Fatima, Z., \& Anderson, A. K. (2007). Attending to the present: Mindfulness meditation reveals distinct neural modes of self-reference. Social Cognitive and Affective Neuroscience, 2, 313-322. https://doi.org/10.1093/scan/nsm030

Faul, F., Erdfelder, E., Lang, A. G., \& Buchner, A. (2007). G* Power 3: A flexible statistical power analysis program for the social, behavioral, and biomedical sciences. Behavior Research Methods, 39(2), 175-191. https://doi.org/10.3758/bf03193146

Figee, M., Vink, M., de Geus, F., Vulink, N., Veltman, D. J., Westenberg, H., \& Denys, D. (2011). Dysfunctional reward circuitry in obsessive-compulsive disorder. Biological Psychiatry, 69(9), 867-874. https://doi.org/10.1016/j.biopsych.2010.12.003

First, M. B., \& Williams, J. B. (2016). SCID-5-CV: Structured Clinical Interview for DSM-5 Disorders: Clinician Version. Arlington: American Psychiatric Association. 
Foa, E. B., Huppert, J. D., Leiberg, S., Langner, R., Kichic, R., Hajcak, G., \& Salkovskis, P. M. (2002). The Obsessive-Compulsive Inventory: Development and validation of a short version. Psychological Assessment, 14, 485-496. https://doi.org/10.1037/1040-3590.14.4.485

Goldin, P., Ramel, W., \& Gross, J. (2009). Mindfulness meditation training and self-referential processing in social anxiety disorder: Behavioral and neural effects. Journal of Cognitive Psychotherapy, 23(3), 242-257. https://doi.org/10.1891/0889-8391.23.3.242

Grassi, G., Pallanti, S., Righi, L., Figee, M., Mantione, M., Denys, D., .. \& Stratta, P. (2015). Think twice: Impulsivity and decision making in obsessive-compulsive disorder. Journal of Behavioral Addictions, 4(4), 263-272. https://doi.org/10.1556/2006.4.2015.039

Grayson, J. (2013). ACT vs. ERP for OCD: Is it war or marriage? The Behavior Therapist, 36(4), 84-89.

Green, L., \& Myerson, J. (2010). Experimental and correlational analyses of delay and probability discounting. In G. J. Madden \& W. K. Bickel (Eds.), Impulsivity: The behavioral and neurological science of discounting (p. 67-92). American Psychological Association. https://doi.org/10.1037/12069-003

Haque, M. (2020). Handwashing in averting infectious diseases: Relevance to COVID19. Journal of Population Therapeutics and Clinical Pharmacology, 27(SP1), e37-e52. https://doi.org/10.15586/jptcp.v27sp1.711

Heerey, E. A., Robinson, B. M., McMahon, R. P., \& Gold, J. M. (2007). Delay discounting in schizophrenia. Cognitive Neuropsychiatry, 12(3), 213-221. https://doi.org/10.1080/13546800601005900 
Hendrickson, K. L., \& Rasmussen, E. B. (2013). Effects of mindful eating training on delay and probability discounting for food and money in obese and healthy-weight individuals. Behaviour Research and Therapy, 51(7), 399-409. https://doi.org/10.1016/j.brat.2013.04.002

Herman, A. M., Critchley, H. D., \& Duka, T. (2018). Risk-taking and impulsivity: The role of mood states and interoception. Frontiers in Psychology, 9, 1625. https://doi.org/10.3389/fpsyg.2018.01625

Hevey, D., Pertl, M., Thomas, K., Maher, L., Craig, A., \& Chuinneagain, S. N. (2010). Consideration of future consequences scale: Confirmatory factor analysis. Personality and Individual Differences, 48(5), 654-657. https://doi.org/10.1016/j.paid.2010.01.006

Hollander, E., \& Wong, C. M. (1995). Obsessive-compulsive spectrum disorders. The Journal of Clinical Psychiatry, 56(Suppl 4), 3-6.

Hutchins, H. J., Wolff, B., Leeb, R., Ko, J. Y., Odom, E., Willey, J., ... \& Bitsko, R. H. (2020). COVID-19 mitigation behaviors by age group_-United States, April-June 2020. Morbidity and Mortality Weekly Report, 69(43), 1584. https://doi.org/10.15585/mmwr.mm6943e4

Islam, J. Y., Vidot, D. C., \& Camacho-Rivera, M. (2021). Determinants of COVID-19 preventive behaviours among adults with chronic diseases in the USA: An analysis of the nationally representative COVID-19 impact survey. BMJ Open, 11(2). https://doi.org/10.1136/bmjopen-2020-044600

Johnson, S., Gur, R. M., David, Z., \& Currier, E. (2015). One-session mindfulness meditation: A randomized controlled study of effects on cognition and mood. Mindfulness, 6(1), 88-98. https://doi.org/10.1007/s12671-013-0234-6 
Joireman, J., Balliet, D., Sprott, D., Spangenberg, E., \& Schultz, J. (2008). Consideration of future consequences, ego-depletion, and self-control: Support for distinguishing between CFC-Immediate and CFC-Future sub-scales. Personality and Individual Differences, 45(1), 15-21. https://doi.org/10.1016/j.paid.2008.02.011

Jordan, C. H., Wang, W., Donatoni, L., \& Meier, B. P. (2014). Mindful eating: Trait and state mindfulness predict healthier eating behavior. Personality and Individual differences, 68 , 107-111. https://doi.org/10.1016/j.paid.2014.04.013

Kabat-Zinn, J., \& Hanh, T. N. (1990). Full catastrophe living: Using the wisdom of your body and mind to face stress, pain, and illness. New York, NY: Dell.

Kaplan, B. A., Amlung, M., Reed, D. D., Jarmolowicz, D. P., McKerchar, T. L., \& Lemley, S. M. (2016). Automating scoring of delay discounting for the 21-and 27-item Monetary Choice Questionnaires. The Behavior Analyst, 39(2), 293-304. https://doi.org/10.1007/s40614-016-0070-9

Kiken, L. G., \& Shook, N. J. (2011). Looking up: Mindfulness increases positive judgments and reduces negativity bias. Social Psychological and Personality Science, 2(4), 425-431. https://doi.org/10.1177/1948550610396585

Kiken, L. G., \& Shook, N. J. (2014). Does mindfulness attenuate thoughts emphasizing negativity, but not positivity?. Journal of Research in Personality, 53, 22-30. https://doi.org/10.1016/j.jrp.2014.08.002

Kirby, K. N., \& Maraković, N. N. (1996). Delay-discounting probabilistic rewards: Rates decrease as amounts increase. Psychonomic Bulletin \& Review, 3(1), 100-104. https://doi.org/10.3758/bf03210748 
Kirby, K. N., Petry, N. M., \& Bickel, W. K. (1999). Heroin addicts have higher discount rates for delayed rewards than non-drug-using controls. Journal of Experimental Psychology: General, 128(1), 78-87.

Lattal, K. A. (2013). The five pillars of the experimental analysis of behavior. In G. J. Madden (Ed.-in-Chief), W. V. Dube, T. D. Hackenberg, G. P. Hanley, \& K. A. Lattal (Assoc. Eds.), APA handbook of behavior analysis, Vol. 1: Methods and principles. (pp. 32-63). Washington, DC, US: American Psychological Association. https://doi.org/10.1037/13937-002

Leckman, J. F., Grice, D. E., Boardman, J., Zhang, H., Vitale, A., Bondi, C., ... \& Goodman, W. K. (1997). Symptoms of obsessive-compulsive disorder. American Journal of Psychiatry, 154(7), 911-917.

Lempert, K. M., Steinglass, J. E., Pinto, A., Kable, J. W., \& Simpson, H. B. (2019). Can delay discounting deliver on the promise of RDoC?. Psychological Medicine, 49(2), 190-199. https://doi.org/10.1017/s0033291718001770

Leyland, A., Rowse, G., \& Emerson, L. M. (2019). Experimental effects of mindfulness inductions on self-regulation: Systematic review and meta-analysis. Emotion, 19(1), 108122. https://doi.org/10.1037/emo0000425

Lissemore, J. I., Booij, L., Leyton, M., Gravel, P., Sookman, D., Nordahl, T. E., \& Benkelfat, C. (2021). Neuroimaging of Obsessive-Compulsive Disorder: Insights into Serotonergic Mechanisms. In R. A. Dierckx, A. Otte, E. F. J. de Vries, A. van Waarde, \& I. E. Sommer (Eds.) PET and SPECT in Psychiatry (pp. 457-478). Springer, Cham. https://doi.org/10.1007/978-3-030-57231-0_13 
Lovibond, S. H., \& Lovibond, P. F. (1995a). Manual for the Depression Anxiety Stress Scales (2nd ed.). Sydney: Psychology Foundation of Australia.

Lovibond, S. H., \& Lovibond, P. F. (1995b). The structure of negative emotional states:

Comparison of the depression anxiety stress scales (DASS) with the Beck Depression and Anxiety Inventories. Behavioural Research and Therapy, 33, 335-343. https://doi.org/10.1016/0005-7967(94)00075-u

Lueke, A., \& Gibson, B. (2016). Brief mindfulness meditation reduces discrimination. Psychology of Consciousness: Theory, Research, and Practice, 3(1), 34-44. https://doi.org/10.1037/cns0000081

MacKillop, J. (2013). Integrating behavioral economics and behavioral genetics: Delayed reward discounting as an endophenotype for addictive disorders. Journal of the Experimental Analysis of Behavior, 99(1), 14-31. https://doi.org/10.1002/jeab.4

MacKillop, J., Amlung, M. T., Few, L. R., Ray, L. A., Sweet, L. H., \& Munafò, M. R. (2011). Delayed reward discounting and addictive behavior: A meta-analysis. Psychopharmacology, 216(3), 305-321. https://doi.org/10.1007/s00213-011-2229-0

Madden, G. J., \& Johnson, P. S. (2010). A delay-discounting primer. In G. J. Madden \& W. K. Bickel (Eds.), Impulsivity: The Behavioral and Neurological Science of Discounting (pp. 11-37). Washington, DC, US: American Psychological Association. https://doi.org/10.1037/12069-001

Madden, G. J., Raiff, B. R., Lagorio, C. H., Begotka, A. M., Mueller, A. M., Hehli, D. J., \& Wegener, A. A. (2004). Delay discounting of potentially real and hypothetical rewards: II. Between-and within-subject comparisons. Experimental and Clinical Psychopharmacology, 12(4), 251. https://doi.org/10.1037/1064-1297.12.4.251 
Mahalingam, V., Stillwell, D., Kosinski, M., Rust, J., \& Kogan, A. (2014). Who can wait for the future? A personality perspective. Social Psychological and Personality Science, 5(5), 573-583. https://doi.org/10.1177/1948550613515007

Mata, J., Hogan, C. L., Joormann, J., Waugh, C. E., \& Gotlib, I. H. (2013). Acute exercise attenuates negative affect following repeated sad mood inductions in persons who have recovered from depression. Journal of Abnormal Psychology, 122(1), 45-50. https://doi.org/10.1037/a0029881

Mavrogiorgou, P., Enzi, B., Steinmann, S., Mulert, C., \& Juckel, G. (2018). Relationship between neuroanatomical and serotonergic hypotheses of obsessive-compulsive disorder: A combined functional magnetic resonance imaging-evoked potential study. The Journal of Clinical Psychiatry, 79(6). https://doi.org/10.4088/jcp.17m11811

Melli, G., Chiorri, C., Bulli, F., Carraresi, C., Stopani, E., \& Abramowitz, J. (2015). Factor congruence and psychometric properties of the Italian version of the Dimensional Obsessive-Compulsive Scale (DOCS) across non-clinical and clinical samples. Journal of Psychopathology and Behavioral Assessment, 37(2), 329-339. https://doi.org/10.1007/s10862-014-9450-1

Miloyan, B., Bulley, A., \& Suddendorf, T. (2016). Episodic foresight and anxiety: Proximate and ultimate perspectives. British Journal of Clinical Psychology, 55(1), 4-22. https://doi.org/10.1111/bjc.12080

Morrison, A. B., \& Jha, A. P. (2015). Mindfulness, attention, and working memory. In: Ostafin B., Robinson M., Meier B. (Eds). Handbook of mindfulness and self-regulation. Springer, New York, NY. https://doi.org/10.1007/978-1-4939-2263-5_4 
Morrison, K. L., Madden, G. J., Odum, A. L., Friedel, J. E., \& Twohig, M. P. (2014). Altering impulsive decision making with an acceptance-based procedure. Behavior Therapy, 45(5), 630-639. https://doi.org/10.1016/j.beth.2014.01.001

Moulding, R., \& Kyrios, M. (2006). Anxiety disorders and control related beliefs: The exemplar of obsessive-compulsive disorder (OCD). Clinical Psychology Review, 26(5), 573-583. https://doi.org/10.1016/j.cpr.2006.01.009

Murphy, D. L., Timpano, K. R., Wheaton, M. G., Greenberg, B. D., \& Miguel, E. C. (2010). Obsessive-compulsive disorder and its related disorders: A reappraisal of obsessivecompulsive spectrum concepts. Dialogues in Clinical Neuroscience, 12(2), 131-148. https://doi.org/10.31887/dcns.2010.12.2/dmurphy

Odum, A. L. (2011a). Delay discounting: I'm a k, you're a k. Journal of the Experimental Analysis of Behavior, 96(3), 427-439. https://doi.org/10.1901/jeab.2011.96-423

Odum, A. L. (2011b). Delay discounting: Trait variable?. Behavioural processes, 87(1), 1-9. https://doi.org/10.1016/j.beproc.2011.02.007

Odum, A. L., \& Baumann, A. A. L. (2010). Delay discounting: State and trait variable. In G. J. Madden \& W. K. Bickel (Eds.), Impulsivity: The Behavioral and Neurological Science of Discounting (pp. 39-65). Washington, DC, US: American Psychological Association. https://doi.org/10.1037/12069-002

Odum, A. L., Becker, R. J., Haynes, J. M., Galizio, A., Frye, C. C., Downey, H., ... \& Perez, D. M. (2020). Delay discounting of different outcomes: Review and theory. Journal of the Experimental Analysis of Behavior, 113(3), 657-679. https://doi.org/10.1002/jeab.589

Olson, C. A., Hale, L. R., Hamilton, N., Powell, J. N., Martin, L. E., \& Savage, C. R. (2016). Altered source memory retrieval is associated with pathological doubt in obsessive- 
compulsive disorder. Behavioural Brain Research, 296, 53-60. https://doi.org/10.1016/j.bbr.2015.08.031

Ong, C. W., Graves, K., Berry, M. S., Odum, A. L., \& Twohig, M. P. (2018). Obsessivecompulsive symptoms are associated with increased delay discounting in a novel handwashing task. Behavior Analysis: Research and Practice, 19(2), 136-149. https://doi.org/10.1037/bar0000096

Ostafin, B. D., \& Kassman, K. T. (2012). Stepping out of history: Mindfulness improves insight problem solving. Consciousness and Cognition, 21(2), 1031-1036. https://doi.org/10.1016/j.concog.2012.02.014

Patton, J. H., Stanford, M. S., \& Barratt, E. S. (1995). Factor structure of the Barratt Impulsiveness Scale. Journal of Clinical Psychology, 51(6), 768-774. https://doi.org/10.1002/1097-4679(199511)51:6<768::aid-jclp2270510607>3.0.co;2-1

Pauls, D. L. (2010). The genetics of obsessive-compulsive disorder: A review. Dialogues in Clinical Neuroscience, 12(2), 149-163. https://doi.org/10.31887/dcns.2010.12.2/dpauls

Pauls, D. L., Abramovitch, A., Rauch, S. L., \& Geller, D. A. (2014). Obsessive-compulsive disorder: An integrative genetic and neurobiological perspective. Nature Reviews Neuroscience, 15(6), 410-424. https://doi.org/10.1038/nrn3746

Peters, J., \& Büchel, C. (2011). The neural mechanisms of inter-temporal decision-making: Understanding variability. Trends in Cognitive Sciences, 15(5), 227-239. https://doi.org/10.1016/j.tics.2011.03.002

Pinto, A., Steinglass, J. E., Greene, A. L., Weber, E. U., \& Simpson, H. B. (2014). Capacity to delay reward differentiates obsessive-compulsive disorder and obsessive-compulsive personality disorder. Biological Psychiatry, 75(8), 653-659. 
https://doi.org/10.1016/j.biopsych.2013.09.007

Potenza, M. N., Koran, L. M., \& Pallanti, S. (2009). The relationship between impulse-control disorders and obsessive-compulsive disorder: A current understanding and future research directions. Psychiatry Research, 170(1), 22-31. https://doi.org/10.1016/j.psychres.2008.06.036

Pulcu, E., Trotter, P. D., Thomas, E. J., McFarquhar, M., Juhász, G., Sahakian, B. J., ... \& Elliott, R. (2014). Temporal discounting in major depressive disorder. Psychological Medicine, 44(9), 1825-1834. https://doi.org/10.1017/s0033291713002584

Rădulescu, A., \& Marra, R. (2017). A mathematical model of reward and executive circuitry in obsessive compulsive disorder. Journal of Theoretical Biology, 414, 165-175. https://doi.org/10.1016/j.jtbi.2016.11.025

Reynolds, B. (2006). A review of delay-discounting research with humans: Relations to drug use and gambling. Behavioural Pharmacology, 17(8), 651-667. https://doi.org/10.1097/fbp.0b013e3280115f99

Rhéaume, J., Freeston, M. H., Dugas, M. J., Letarte, H., \& Ladouceur, R. (1995). Perfectionism, responsibility and obsessive-compulsive symptoms. Behaviour Research and Therapy, 33(7), 785-794. https://doi.org/10.1016/0005-7967(95)00017-r

Rounds, J. S., Beck, J. G., \& Grant, D. M. (2007). Is the delay discounting paradigm useful in understanding social anxiety?. Behaviour Research and Therapy, 45(4), 729-735. https://doi.org/10.1016/j.brat.2006.06.007

Rung, J. M., \& Madden, G. J. (2018). Experimental reductions of delay discounting and impulsive choice: A systematic review and meta-analysis. Journal of Experimental Psychology: General, 147(9), 1349-1381. https://doi.org/10.1037/xge0000462 
Ruscio, A. M., Stein, D. J., Chiu, W. T., \& Kessler, R. C. (2010). The epidemiology of obsessive-compulsive disorder in the National Comorbidity Survey Replication. Molecular Psychiatry, 15(1), 53-63. https://doi.org/10.1038/mp.2008.94

Sackett, D. A., Moschak, T. M., \& Carelli, R. M. (2019). Prelimbic cortical neurons track preferred reward value and reflect impulsive choice during delay discounting behavior. Journal of Neuroscience, 39(16), 3108-3118. https://doi.org/10.1523/jneurosci.2532-18.2019

Saddoris, M. P., Sugam, J. A., Stuber, G. D., Witten, I. B., Deisseroth, K., \& Carelli, R. M. (2015). Mesolimbic dopamine dynamically tracks, and is causally linked to, discrete aspects of value-based decision making. Biological Psychiatry, 77(10), 903-911. https://doi.org/10.1016/j.biopsych.2014.10.024

Sayers, W. M., Creswell, J. D., Taren, A. (2015). The emerging neurobiology of mindfulness and emotion processing. In: Ostafin B., Robinson M., Meier B. (Eds). Handbook of mindfulness and self-regulation. Springer, New York, NY. https://doi.org/10.1007/978-1-4939-2263-5_2

Scholten, H., Scheres, A., De Water, E., Graf, U., Granic, I., \& Luijten, M. (2019). Behavioral trainings and manipulations to reduce delay discounting: A systematic review. Psychonomic Bulletin \& Review, 26(6), 1803-1849. https://doi.org/10.3758/s13423-019-01629-2

Schumer, M. C., Lindsay, E. K., \& Creswell, J. D. (2018). Brief mindfulness training for negative affectivity: A systematic review and meta-analysis. Journal of Consulting and Clinical Psychology, 86(7), 569-583. https://doi.org/10.1037/ccp0000324 
Senecal, N., Wang, T., Thompson, E., \& Kable, J. W. (2012). Normative arguments from experts and peers reduce delay discounting. Judgment and Decision Making, 7(5), 568-589. PMID: 23596504

Siegel, R. D., Germer, C. K., \& Olendzki, A. (2009). Mindfulness: What is it? Where did it come from?. In Didonna F. (Ed.), Clinical handbook of mindfulness (pp. 17-35). Springer, New York, NY. https://doi.org/10.1007/978-0-387-09593-6_2

Sinclair, S. J., Siefert, C. J., Slavin-Mulford, J. M., Stein, M. B., Renna, M., \& Blais, M. A. (2012). Psychometric evaluation and normative data for the Depression, Anxiety, and Stress Scales-21 (DASS-21) in a nonclinical sample of US adults. Evaluation \& the Health Professions, 35(3), 259-279. https://doi.org/10.1177/0163278711424282

Sinopoli, V. M., Burton, C. L., Kronenberg, S., \& Arnold, P. D. (2017). A review of the role of serotonin system genes in obsessive-compulsive disorder. Neuroscience \& Biobehavioral Reviews, 80, 372-381. https://doi.org/10.1016/j.neubiorev.2017.05.029

Skodol, A. E., \& Oldham, J. M. (1996). Phenomenology, differential diagnosis, and comorbidity of the impulsive-compulsive spectrum of disorders. In J. M. Oldham, E. Hollander, \& A. E. Skodol (Eds.), Impulsivity and compulsivity (pp. 1-36). Arlington, VA, US: American Psychiatric Association.

Sohn, S. Y., Kang, J. I., Namkoong, K., \& Kim, S. J. (2014). Multidimensional measures of impulsivity in obsessive-compulsive disorder: Cannot wait and stop. PLoS One, 9(11). https://doi.org/10.1371/journal.pone.0111739

Solnick, J. V., Kannenberg, C. H., Eckerman, D. A., \& Waller, M. B. (1980). An experimental analysis of impulsivity and impulse control in humans. Learning and Motivation, 11(1), 61-77. https://doi.org/10.1016/0023-9690(80)90021-1 
Stanford, M. S., Mathias, C. W., Dougherty, D. M., Lake, S. L., Anderson, N. E., \& Patton, J. H. (2009). Fifty years of the Barratt Impulsiveness Scale: An update and review. Personality and Individual Differences, 47(5), 385-395. https://doi.org/10.1016/j.paid.2009.04.008

Stanger, C., Ryan, S. R., Fu, H., Landes, R. D., Jones, B. A., Bickel, W. K., \& Budney, A. J. (2012). Delay discounting predicts adolescent substance abuse treatment outcome. Experimental and Clinical Psychopharmacology, 20(3), 205-212. https://doi.org/10.1037/a0026543

Steinglass, J. E., Figner, B., Berkowitz, S., Simpson, H. B., Weber, E. U., \& Walsh, B. T. (2012). Increased capacity to delay reward in anorexia nervosa. Journal of the International Neuropsychological Society, 18(4), 773-780. https://doi.org/10.1017/S1355617712000446

Steinglass, J. E., Lempert, K. M., Choo, T. H., Kimeldorf, M. B., Wall, M., Walsh, B. T., ... \& Simpson, H. B. (2017). Temporal discounting across three psychiatric disorders: Anorexia nervosa, obsessive compulsive disorder, and social anxiety disorder. Depression and Anxiety, 34(5), 463-470. https://doi.org/10.1002/da.22586

Steketee, G. (Ed.). (2011). The Oxford handbook of obsessive compulsive and spectrum disorders. Oxford University Press.

Strathman, A., Gleicher, F., Boninger, D. S., \& Edwards, C. S. (1994). The consideration of future consequences: Weighing immediate and distant outcomes of behavior. Journal of Personality and Social Psychology, 66(4), 742-752.

https://doi.org/10.1037/0022-3514.66.4.742 
Taylor, V. A., Grant, J., Daneault, V., Scavone, G., Breton, E., Roffe-Vidal, S., ... \& Beauregard, M. (2011). Impact of mindfulness on the neural responses to emotional pictures in experienced and beginner meditators. Neuroimage, 57(4), 1524-1533. https://doi.org/10.1016/j.neuroimage.2011.06.001

Teuscher, U., \& Mitchell, S. H. (2011). Relation between time perspective and delay discounting: A literature review. The Psychological Record, 61(4), 613-632. https://doi.org/10.1007/bf03395780

Tolin, D. F., Gilliam, C., Wootton, B. M., Bowe, W., Bragdon, L. B., Davis, E., ... \& Hallion, L. S. (2018). Psychometric properties of a structured diagnostic interview for DSM-5 anxiety, mood, and obsessive-compulsive and related disorders. Assessment, 25(1), 3-13. https://doi.org/10.1177/1073191116638410

Twohig, M. P., Hayes, S. C., \& Masuda, A. (2006). Increasing willingness to experience obsessions: Acceptance and commitment therapy as a treatment for obsessive-compulsive disorder. Behavior Therapy, 37(1), 3-13. https://doi.org/10.1016/j.beth.2005.02.001

Twohig, M.P., Hayes, S.C., Plumb, J.C., Pruitt, L.D., Collins, A.B., Hazlett-Stevens, H., \& Woidneck, M.R. (2010). A randomized clinical trial of acceptance and commitment therapy versus progressive relaxation training for obsessive-compulsive disorder. Journal of Consulting and Clinical Psychology, 78, 705-716. https://doi.org/10.1037/a0020508

Voon, V., \& Dalley, J. W. (2015). Translatable and back-translatable measurement of impulsivity and compulsivity: Convergent and divergent processes. In: Robbins T.W., Sahakian B.J. (Eds.), Translational Neuropsychopharmacology, (pp. 53-91). Springer, Cham. https://doi.org/10.1007/7854_2015_5013 
Walach, H., Buchheld, N., Buttenmüller, V., Kleinknecht, N., \& Schmidt, S. (2006). Measuring mindfulness-the Freiburg mindfulness inventory (FMI). Personality and Individual Differences, 40(8), 1543-1555. https://doi.org/10.1016/j.paid.2005.11.025

Weatherly, J. N. (2012). Aspects of compulsiveness are inversely related to rates of delay discounting. The Behavior Analyst Today, 13(2), 22-26. https://doi.org/10.1037/h0100721

Weinstein, N., Brown, K. W., \& Ryan, R. M. (2009). A multi-method examination of the effects of mindfulness on stress attribution, coping, and emotional well-being. Journal of Research in Personality, 43(3), 374-385. https://doi.org/10.1016/j.jrp.2008.12.008

Wheaton, M. G., Abramowitz, J. S., Berman, N. C., Riemann, B. C., \& Hale, L. R. (2010). The relationship between obsessive beliefs and symptom dimensions in obsessive-compulsive disorder. Behaviour Research and Therapy, 48(10), 949-954. https://doi.org/10.1016/j.brat.2010.05.027

Williams, M. T., Rouleau, T. M., La Torre, J. T., \& Sharif, N. (2020). Cultural competency in the treatment of obsessive-compulsive disorder: Practitioner guidelines. The Cognitive Behaviour Therapist, 13. https://doi.org/10.1017/S1754470X20000501

Worthy, D. A., Byrne, K. A., \& Fields, S. (2014). Effects of emotion on prospection during decision-making. Frontiers in Psychology, 5, 591. https://doi.org/10.3389/fpsyg.2014.00591

Wu, K., Hanna, G. L., Rosenberg, D. R., \& Arnold, P. D. (2012). The role of glutamate signaling in the pathogenesis and treatment of obsessive-compulsive disorder. Pharmacology Biochemistry and Behavior, 100(4), 726-735. https://doi.org/10.1016/j.pbb.2011.10.007

Xia, L., Gu, R., Zhang, D., \& Luo, Y. (2017). Anxious individuals are impulsive decision- 
makers in the delay discounting task: An ERP study. Frontiers in Behavioral Neuroscience, 11, 5. https://doi.org/10.3389/fnbeh.2017.00005

Zeidan, F., Johnson, S. K., Gordon, N. S., \& Goolkasian, P. (2010). Effects of brief and sham mindfulness meditation on mood and cardiovascular variables. The Journal of Alternative and Complementary Medicine, 16(8), 867-873. https://doi.org/10.1089/acm.2009.0321

Zeidan, F., Martucci, K. T., Kraft, R. A., Gordon, N. S., McHaffie, J. G., \& Coghill, R. C. (2011). Brain mechanisms supporting the modulation of pain by mindfulness meditation. Journal of Neuroscience, 31(14), 5540-5548. https://doi.org/10.1523/jneurosci.5791-10.2011

Zhao, J., Cheng, J., Harris, M., \& Vigo, R. (2015). Anxiety and intertemporal decision making: The effect of the behavioral inhibition system and the moderation effects of trait anxiety on both state anxiety and socioeconomic status. Personality and Individual Differences, 87, 236-241. https://doi.org/10.1016/j.paid.2015.08.018 
Table 1

Descriptive statistics for all Study 1 measures by condition

\begin{tabular}{lcccccc}
\hline & \multicolumn{2}{c}{ Mindfulness Condition $(n=40)$} & \multicolumn{2}{c}{ Control Condition $(n=44)$} \\
\hline Measure & Mean & SD & Range & Mean & SD & Range \\
\hline OCI-R & 24.83 & 10.55 & $11-47$ & 26.00 & 11.57 & $9-52$ \\
MAAS-S & 17.58 & 7.40 & $3-29$ & 17.07 & 7.53 & $1-29$ \\
AQ1 & 4.90 & 1.30 & $2-7$ & 4.32 & 1.34 & $1-7$ \\
AQ2 & 2.70 & 1.82 & $1-7$ & 2.75 & 1.56 & $1-7$ \\
MCQ-27 & .03 & .03 & $.0002-.1178$ & .02 & .03 & $.0002-.1843$ \\
HDDT & .11 & .10 & $.0025-.2525$ & .09 & .08 & $.0045-.2525$ \\
DOCS & 24.68 & 13.07 & $1-52$ & 22.98 & 11.34 & $3-52$ \\
FMI & 31.68 & 7.61 & $19-50$ & 33.23 & 4.46 & $23-44$ \\
DASS-D & 7.68 & 5.23 & $0-19$ & 5.95 & 4.53 & $0-16$ \\
DASS-A & 7.00 & 4.76 & $0-17$ & 5.57 & 4.41 & $0-16$ \\
DASS-S & 10.20 & 4.86 & $0-20$ & 8.34 & 3.95 & $2-16$ \\
CFCS & 36.57 & 4.00 & $28-45$ & 36.70 & 4.58 & $29-50$ \\
BIS-11 & 71.46 & 7.31 & $60-89$ & 69.05 & 7.17 & $55-85$ \\
\hline
\end{tabular}

Note: OCI-R = Obsessive-Compulsive Inventory-Revised, MAAS-S = Mindful Attention Awareness Scale-State, AQ1 = Affect Question-Positive, AQ2 = Affect Question-Negative, MCQ-27 = Monetary Choice Questionnaire-27, HDDT = Handwashing Delay Discounting Task, DOCS - Dimensional Obsessive-Compulsive Scale, FMI = Freiburg Mindfulness Inventory, DASS-D = Depression subscale of DASS-21, DASS-A = Anxiety subscale of the DASS-21, DASS-S = Stress subscale of the DASS-21, CFCS = Consideration of Future Consequences Scale, BIS-11 = Barratt Impulsiveness Scale 11 


\section{Table 2}

Pearson's correlation coefficients among delay discounting tasks and Study 1 measures.

\begin{tabular}{|c|c|c|c|c|c|c|c|c|c|c|c|c|}
\hline Variable & 1 & 2 & 3 & 4 & 5 & 6 & 7 & 8 & 9 & 10 & 11 & 12 \\
\hline \multicolumn{13}{|l|}{ 1. MCQ-21 } \\
\hline 2. MCQ-27 & $.66^{* * * *}$ & & & & & & & & & & & \\
\hline 3. HDDT & .11 & $.25^{*}$ & & & & & & & & & & \\
\hline 4. OCI-R & .09 & .06 & .17 & & & & & & & & & \\
\hline 5. OCI-R-W & -.04 & -.03 & $.42 * * *$ & $.64 * * *$ & & & & & & & & \\
\hline 6. DOCS & .08 & .16 & .17 & $.72 * * *$ & $.36 * *$ & & & & & & & \\
\hline 7. DOCS-C & .02 & .12 & $.32 * *$ & $.63 * * *$ & $.71 * * *$ & $.72 * * *$ & & & & & & \\
\hline 8. FMI & .16 & -.01 & -.13 & -.11 & .10 & -.19 & .02 & & & & & \\
\hline 9. DASS-D & .01 & .03 & -.14 & $.29 * *$ & .01 & $.25^{*}$ & -.10 & $-.37 * * *$ & & & & \\
\hline 10. DASS-A & .08 & .12 & .10 & $.51 * * *$ & $.26^{*}$ & $.50 * * *$ & $.33 * *$ & $-.29 * *$ & $.51 * * *$ & & & \\
\hline 11. DASS-S & -.12 & -.01 & -.06 & $.50 * * *$ & .21 & $.43 * * *$ & .21 & $-.42 * * *$ & $.61 * * *$ & $.72 * * *$ & & \\
\hline 12. CFCS & .11 & .15 & -.04 & .12 & .09 & .15 & .04 & -.01 & .18 & $.26^{*}$ & .21 & \\
\hline 13. BIS-11 & .06 & .03 & -.06 & $.43 * * *$ & $.24 *$ & $.36 * *$ & $.26^{*}$ & -.04 & $.31 * *$ & $.32 * *$ & $.39 * * *$ & $.24 *$ \\
\hline
\end{tabular}

Note: MCQ-21 = Monetary Choice Questionnaire-21, MCQ-27 = Monetary Choice Questionnaire-27, HDDT = Handwashing Delay Discounting Task, OCI-R = Obsessive-Compulsive Inventory-Revised, OCI-R-W = Washing subscale of OCI-R, DOCS = Dimensional Obsessive-Compulsive Scale, DOCS-C = Contamination subscale of DOCS, FMI = Freiburg Mindfulness Inventory, DASS-D = Depression subscale of DASS-21, DASS-A = Anxiety subscale of the DASS-21, DASS-S = Stress subscale of the DASS21, CFCS = Consideration of Future Consequences Scale, BIS-11 = Barratt Impulsiveness Scale 11

$* p<.05, * * p<.01, * * * p<.001$ 
Table 3

Descriptive statistics for all Study 2 measures by condition

\begin{tabular}{lcccccc}
\hline & \multicolumn{3}{c}{ Mindfulness Condition $(n=39)$} & \multicolumn{3}{c}{ Control Condition $(n=40)$} \\
\hline Measure & Mean & SD & Range & Mean & SD & Range \\
\hline OCI-R & 28.05 & 10.10 & $10-52$ & 32.75 & 15.54 & $9-58$ \\
MAAS-S & 15.90 & 5.23 & $5-26$ & 16.38 & 6.23 & $2-30$ \\
AQ1 & 4.85 & 1.16 & $3-7$ & 4.42 & 1.34 & $2-7$ \\
AQ2 & 2.97 & 1.39 & $1-6$ & 3.55 & 1.58 & $1-6$ \\
MCQ-27 & .02 & .03 & $.0002-.1588$ & .02 & .03 & $.0002-.1588$ \\
HDDT & .11 & .09 & $.0029-.2525$ & .12 & .10 & $.0035-.2525$ \\
DOCS & 26.50 & 11.85 & $7-56$ & 27.74 & 15.78 & $3-52$ \\
FMI & 35.24 & 5.26 & $26-49$ & 35.30 & 7.00 & $23-44$ \\
DASS-D & 6.92 & 5.14 & $0-20$ & 7.72 & 5.77 & $0-16$ \\
DASS-A & 7.36 & 5.67 & $0-21$ & 7.05 & 5.03 & $0-16$ \\
DASS-S & 9.64 & 4.46 & $3-20$ & 8.57 & 4.71 & $2-16$ \\
CFCS & 43.21 & 7.45 & $30-56$ & 42.88 & 7.55 & $29-50$ \\
BIS-11 & 63.21 & 11.06 & $45-91$ & 62.85 & 10.24 & $40-89$ \\
\hline
\end{tabular}

Note: OCI-R = Obsessive-Compulsive Inventory-Revised, MAAS-S = Mindful Attention Awareness Scale-State, AQ1 = Affect Question-Positive, AQ2 = Affect Question-Negative, MCQ-27 = Monetary Choice Questionnaire-27, HDDT $=$ Handwashing Delay Discounting Task, DOCS - Dimensional Obsessive-Compulsive Scale, FMI = Freiburg Mindfulness Inventory, DASS-D = Depression subscale of DASS-21, DASS-A = Anxiety subscale of the DASS-21, DASS-S $=$ Stress subscale of the DASS-21, CFCS $=$ Consideration of Future Consequences Scale, BIS-11 = Barratt Impulsiveness Scale 11 


\section{Table 4}

Pearson's correlation coefficients among delay discounting tasks and Study 2 measures.

\begin{tabular}{|c|c|c|c|c|c|c|c|c|c|c|c|c|}
\hline Variable & 1 & 2 & 3 & 4 & 5 & 6 & 7 & 8 & 9 & 10 & 11 & 12 \\
\hline \multicolumn{13}{|l|}{ 1. MCQ-21 } \\
\hline 2. MCQ-27 & $.60 * * *$ & & & & & & & & & & & \\
\hline 3. HDDT & .18 & .12 & & & & & & & & & & \\
\hline 4. OCI-R & .11 & .10 & $.22 *$ & & & & & & & & & \\
\hline 5. OCI-R-W & .07 & -.002 & .17 & $.69 * * *$ & & & & & & & & \\
\hline 6. DOCS & -.05 & -.06 & $.23 *$ & $.77 * * *$ & $.60 * * *$ & & & & & & & \\
\hline 7. DOCS-C & -.04 & -.08 & $.32 * *$ & $.57 * * *$ & $.80 * * *$ & $.71 * * *$ & & & & & & \\
\hline 8. FMI & .02 & -.03 & .08 & -.11 & -.04 & $-.24 *$ & -.004 & & & & & \\
\hline 9. DASS-D & -.13 & -.19 & .03 & $.40 * *$ & .18 & $.52 * * *$ & .19 & $-.30 * *$ & & & & \\
\hline 10. DASS-A & -.05 & -.02 & .03 & $.51 * * *$ & $.30 * *$ & $.60 * * *$ & $.33 * *$ & $-.25^{*}$ & $.68 * * *$ & & & \\
\hline 11. DASS-S & -.10 & -.17 & .03 & $.43 * * *$ & .20 & $.58 * * *$ & $.30 * *$ & $-.30 * *$ & $.74 * * *$ & $.75 * * *$ & & \\
\hline 12. CFCS & -.05 & -.08 & .11 & .15 & $.26 *$ & .13 & $.25 *$ & .003 & -.08 & -.16 & -.02 & \\
\hline 13. BIS-11 & -.05 & -.09 & -.03 & .15 & -.02 & .17 & -.03 & -.13 & $.31 * *$ & $.38 * *$ & $.35 * *$ & $-.56 * * *$ \\
\hline
\end{tabular}

Note: MCQ-21 = Monetary Choice Questionnaire-21, MCQ-27 = Monetary Choice Questionnaire-27, HDDT = Handwashing Delay Discounting Task, OCI-R = Obsessive-Compulsive Inventory-Revised, OCI-R-W = Washing subscale of OCI-R, DOCS = Dimensional Obsessive-Compulsive Scale, DOCS-C = Contamination subscale of DOCS, FMI = Freiburg Mindfulness Inventory, DASS-D = Depression subscale of DASS-21, DASS-A = Anxiety subscale of the DASS-21, DASS-S = Stress subscale of the DASS21, CFCS $=$ Consideration of Future Consequences Scale, BIS-11 = Barratt Impulsiveness Scale 11

$* p<.05, * * p<.01, * * * p<.001$ 


\section{Figure 1}

Order effect on HDDT discount rate in Study 1

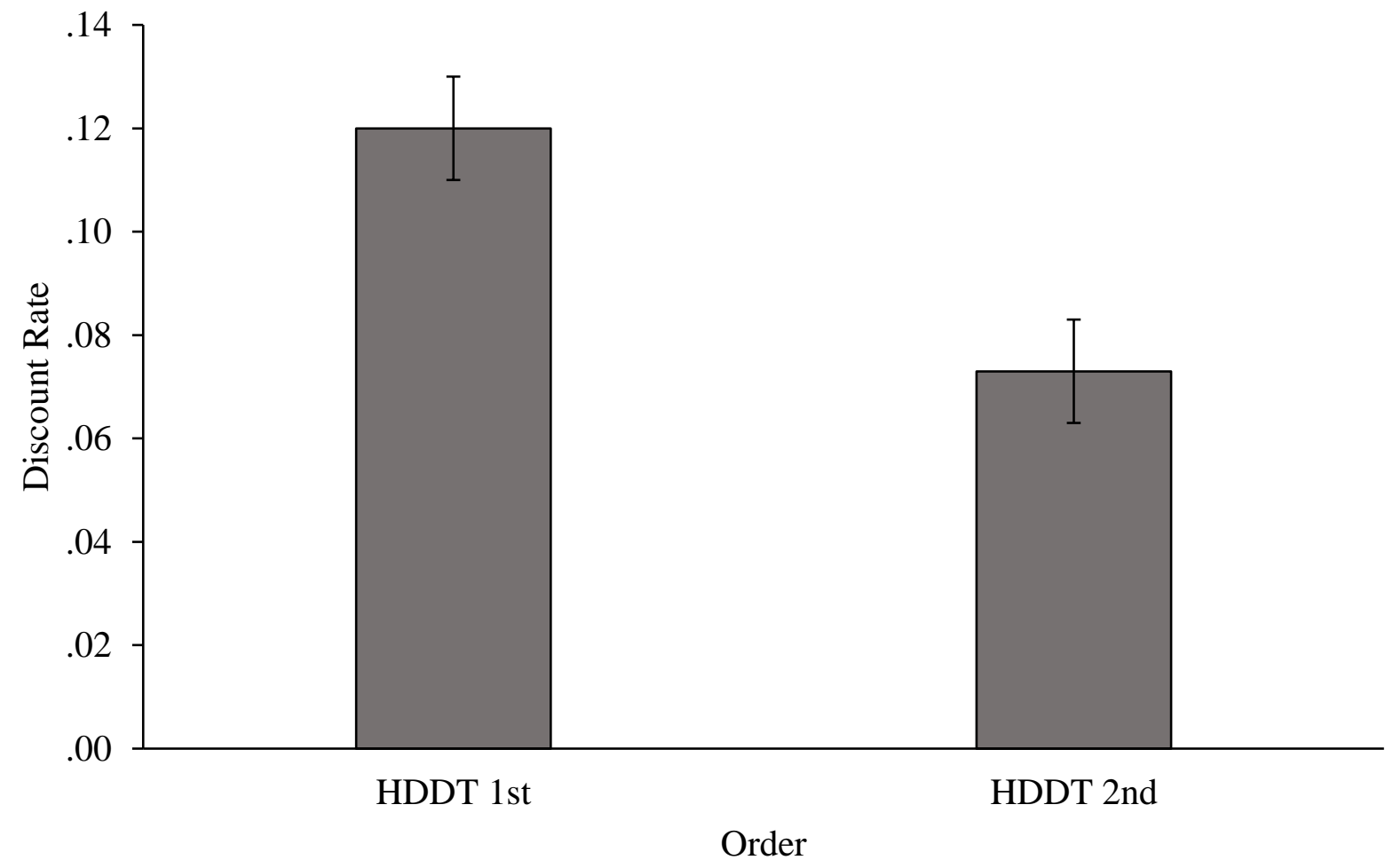




\section{Appendix A}

Obsessive-Compulsive Inventory - Revised (OCI-R)

The following statements refer to experiences that many people have in their everyday lives. Circle the number that best describes HOW MUCH that experience has DISTRESSED or BOTHERED you during the PAST MONTH. The numbers refer to the following verbal labels:

\begin{tabular}{c|c|c|c|c}
\hline 0 & 1 & 2 & 3 & 4 \\
Not at all & A little & Moderately & A lot & Extremely \\
\hline
\end{tabular}

1. I have saved up so many things that they get in the way.

2. I check things more often than necessary.

3. I get upset if objects are not arranged properly.

4. I feel compelled to count while I am doing things.

5. I find it difficult to touch an object when I know it has beentouched by strangers or certain people.

6. I find it difficult to control my own thoughts.

7. I collect things I don't need.

8. I repeatedly check doors, windows, drawers, etc.

9. I get upset if others change the way I have arranged things.

10. I feel I have to repeat certain numbers.

11. I sometimes have to wash or clean myself simply because I feel contaminated. $\begin{array}{lllll}0 & 1 & 2 & 3 & 4\end{array}$

$\begin{array}{lllll}0 & 1 & 2 & 3 & 4\end{array}$

$\begin{array}{lllll}0 & 1 & 2 & 3 & 4\end{array}$

$\begin{array}{lllll}0 & 1 & 2 & 3 & 4\end{array}$

$\begin{array}{lllll}0 & 1 & 2 & 3 & 4\end{array}$

$\begin{array}{lllll}0 & 1 & 2 & 3 & 4\end{array}$

$\begin{array}{lllll}0 & 1 & 2 & 3 & 4\end{array}$

$\begin{array}{lllll}0 & 1 & 2 & 3 & 4\end{array}$

$\begin{array}{lllll}0 & 1 & 2 & 3 & 4\end{array}$

$\begin{array}{lllll}0 & 1 & 2 & 3 & 4\end{array}$

$\begin{array}{lllll}0 & 1 & 2 & 3 & 4\end{array}$

12. I am upset by unpleasant thoughts that come into my mind against my will. $\quad \begin{array}{llllll}0 & 1 & 2 & 3 & 4\end{array}$

13. I avoid throwing things away because I am afraid I might need them later. $\quad \begin{array}{lllll}0 & 1 & 2 & 3 & 4\end{array}$

14. I repeatedly check gas and water taps and light switches after turning them $\quad \begin{array}{llllll}0 & 1 & 2 & 3 & 4\end{array}$ off.

15. I need things to be arranged in a particular way.

$\begin{array}{lllll}0 & 1 & 2 & 3 & 4\end{array}$ 
16. I feel that there are good and bad numbers.

17. I wash my hands more often and longer than necessary.

18. I frequently get nasty thoughts and have difficulty in getting rid of them. $\begin{array}{lllll}0 & 1 & 2 & 3 & 4\end{array}$

$\begin{array}{lllll}0 & 1 & 2 & 3 & 4\end{array}$

$\begin{array}{lllll}0 & 1 & 2 & 3 & 4\end{array}$ 


\section{Appendix B}

\section{Dimensional Obsessive-Compulsive Scale (DOCS)}

This questionnaire asks you about 4 different types of concerns that you might or might not experience. For each type there is a description of the kinds of thoughts (sometimes called obsessions) and behaviors (sometimes called rituals or compulsions) that are typical of that particular concern, followed by 5 questions about your experiences with these thoughts and behaviors. Please read each description carefully and answer the questions for each category based on your experiences in the last month.

\section{Category 1: Concerns about Germs and Contamination}

Examples...

-Thoughts or feelings that you are contaminated because you came into contact with (or were nearby) a certain object or person.

-The feeling of being contaminated because you were in a certain place (such as a bathroom).

-Thoughts about germs, sickness, or the possibility of spreading contamination.

-Washing your hands, using hand sanitizer gels, showering, changing your clothes, or cleaning objects because of concerns about contamination.

-Following a certain routine (e.g., in the bathroom, getting dressed) because of contamination -Avoiding certain people, objects, or places because of contamination.

The next questions ask about your experiences with thoughts and behaviors related to contamination over the last month. Keep in mind that your experiences might be different than the examples listed above. Please select the number next to your answer:

1. About how much time have you spent each day thinking about contamination and engaging in washing or cleaning behaviors because of contamination?

$0 \quad$ None at all

$1 \quad$ Less than 1 hour each day

$2 \quad$ Between 1 and 3 hours each day

3 Between 3 and 8 hours each day

48 hours or more each day

2. To what extent have you avoided situations in order to prevent concerns with contamination or having to spend time washing, cleaning, or showering?

$0 \quad$ None at all

1 A little avoidance

2 A moderate amount of avoidance

3 A great deal of avoidance

$4 \quad$ Extreme avoidance of nearly all things

3. If you had thoughts about contamination but could not wash, clean, or shower (or otherwise remove the contamination), how distressed or anxious did you become?

$0 \quad$ Not at all distressed/anxious

1 Mildly distressed/anxious 
$2 \quad$ Moderately distressed/anxious

3 Severely distressed/anxious

4 Extremely distressed/anxious

4. To what extent has your daily routine (work, school, self-care, social life) been disrupted by contamination concerns and excessive washing, showering, cleaning, or avoidance behaviors?

$0 \quad$ No disruption at all.

$1 \quad$ A little disruption, but I mostly function well.

2 Many things are disrupted, but I can still manage.

$3 \quad$ My life is disrupted in many ways and I have trouble managing.

$4 \quad$ My life is completely disrupted and I cannot function at all.

5. How difficult is it for you to disregard thoughts about contamination and refrain from behaviors such as washing, showering, cleaning, and other decontamination routines when you try to do so?

$0 \quad$ Not at all difficult

$1 \quad$ A little difficult

$2 \quad$ Moderately difficult

$3 \quad$ Very difficult

$4 \quad$ Extremely difficult

\section{Category 2: Concerns about being Responsible for Harm, Injury, or Bad Luck}

Examples...

-A doubt that you might have made a mistake that could cause something awful or harmful to happen.

-The thought that a terrible accident, disaster, injury, or other bad luck might have occurred and you weren't careful enough to prevent it.

-The thought that you could prevent harm or bad luck by doing things in a certain way, counting to certain numbers, or by avoiding certain "bad" numbers or words.

-Thought of losing something important that you are unlikely to lose (e.g., wallet, identify theft, papers).

-Checking things such as locks, switches, your wallet, etc. more often than is necessary.

-Repeatedly asking or checking for reassurance that something bad did not (or will not)

happen.

-Mentally reviewing past events to make sure you didn't do anything wrong.

-The need to follow a special routine because it will prevent harm or disasters from occurring.

-The need to count to certain numbers, or avoid certain bad numbers, due to the fear of harm.

The next questions ask about your experiences with thoughts and behaviors related to harm and disasters over the last month. Keep in mind that your experiences might be slightly different than the examples listed above. Please select the number next to your answer:

1. About how much time have you spent each day thinking about the possibility of harm or disasters and engaging in checking or efforts to get reassurance that such things do not (or did not) occur?

$0 \quad$ None at all

1 Less than 1 hour each day

$2 \quad$ Between 1 and 3 hours each day

3 Between 3 and 8 hours each day 
48 hours or more each day

2. To what extent have you avoided situations so that you did not have to check for danger or worry about possible harm or disasters?

$0 \quad$ None at all

$1 \quad$ A little avoidance

2 A moderate amount of avoidance

3 A great deal of avoidance

4 Extreme avoidance of nearly all things

3. When you think about the possibility of harm or disasters, or if you cannot check or get reassurance about these things, how distressed or anxious did you become?

$0 \quad$ Not at all distressed/anxious

$1 \quad$ Mildly distressed/anxious

2 Moderately distressed/anxious

3 Severely distressed/anxious

4 Extremely distressed/anxious

4. To what extent has your daily routine (work, school, self-care, social life) been disrupted by thoughts about harm or disasters and excessive checking or asking for reassurance?

$0 \quad$ No disruption at all.

$1 \quad$ A little disruption, but I mostly function well.

2 Many things are disrupted, but I can still manage.

$3 \quad$ My life is disrupted in many ways and I have trouble managing.

$4 \quad$ My life is completely disrupted and I cannot function at all.

5. How difficult is it for you to disregard thoughts about possible harm or disasters and refrain from checking or reassurance-seeking behaviors when you try to do so?

$0 \quad$ Not at all difficult

$1 \quad$ A little difficult

2 Moderately difficult

$3 \quad$ Very difficult

$4 \quad$ Extremely difficult

\section{Category 3: Unacceptable Thoughts}

Examples...

-Unpleasant thoughts about sex, immorality, or violence that come to mind against your will.

-Thoughts about doing awful, improper, or embarrassing things that you don't really want to do.

-Repeating an action or following a special routine because of a bad thought.

-Mentally performing an action or saying prayers to get rid of an unwanted or unpleasant thought.

-Avoidance of certain people, places, situations or other triggers of unwanted or unpleasant thoughts

The next questions ask about your experiences with unwanted thoughts that come to mind against your will and behaviors designed to deal with these kinds of thoughts over the last 
month. Keep in mind that your experiences might be slightly different than the examples listed above. Please select the number next to your answer:

1. About how much time have you spent each day with unwanted unpleasant thoughts and with behavioral or mental actions to deal with them?

$0 \quad$ None at all

1 Less than 1 hour each day

$2 \quad$ Between 1 and 3 hours each day

3 Between 3 and 8 hours each day

48 hours or more each day

2. To what extent have you been avoiding situations, places, objects and other reminders (e.g., numbers, people) that trigger unwanted or unpleasant thoughts?

$0 \quad$ None at all

$1 \quad$ A little avoidance

2 A moderate amount of avoidance

3 A great deal of avoidance

4 Extreme avoidance of nearly all things

3. When unwanted or unpleasant thoughts come to mind against your will how distressed or anxious did you become?

$0 \quad$ Not at all distressed/anxious

$1 \quad$ Mildly distressed/anxious

2 Moderately distressed/anxious

3 Severely distressed/anxious

4 Extremely distressed/anxious

4. To what extent has your daily routine (work, school, self-care, social life) been disrupted by unwanted and unpleasant thoughts and efforts to avoid or deal with such thoughts?

$0 \quad$ No disruption at all.

$1 \quad$ A little disruption, but I mostly function well.

$2 \quad$ Many things are disrupted, but I can still manage.

3 My life is disrupted in many ways and I have trouble managing.

$4 \quad$ My life is completely disrupted and I cannot function at all.

5. How difficult is it for you to disregard unwanted or unpleasant thoughts and refrain from using behavioral or mental acts to deal with them when you try to do so?

$0 \quad$ Not at all difficult

$1 \quad$ A little difficult

2 Moderately difficult

$3 \quad$ Very difficult 


\section{Category 4: Concerns about Symmetry, Completeness, and the Need for Things to be "Just Right" \\ Examples... \\ -The need for symmetry, evenness, balance, or exactness. \\ -Feelings that something isn't "just right." \\ -Repeating a routine action until it feels "just right" or "balanced." \\ -Counting senseless things (e.g., ceiling tiles, words in a sentence). \\ -Unnecessarily arranging things in "order." \\ -Having to say something over and over in the same way until it feels "just right."}

The next questions ask about your experiences with feelings that something is not "just right" and behaviors designed to achieve order, symmetry, or balance over the last month. Keep in mind that your experiences might be slightly different than the examples listed above. Please select the number next to your answer:

1. About how much time have you spent each day with unwanted thoughts about symmetry, order, or balance and with behaviors intended to achieve symmetry, order or balance?

$0 \quad$ None at all

$1 \quad$ Less than 1 hour each day

$2 \quad$ Between 1 and 3 hours each day

3 Between 3 and 8 hours each day

48 hours or more each day

2. To what extent have you been avoiding situations, places or objects associated with feelings that something is not symmetrical or "just right?"

$0 \quad$ None at all

$1 \quad$ A little avoidance

2 A moderate amount of avoidance

3 A great deal of avoidance

4 Extreme avoidance of nearly all things

3. When you have the feeling of something being "not just right," how distressed or anxious did you become?

$0 \quad$ Not at all distressed/anxious

$1 \quad$ Mildly distressed/anxious

2 Moderately distressed/anxious

3 Severely distressed/anxious

4 Extremely distressed/anxious

4. To what extent has your daily routine (work, school, self-care, social life) been disrupted by the feeling of things being "not just right," and efforts to put things in order or make them feel right?

$0 \quad$ No disruption at all.

$1 \quad$ A little disruption, but I mostly function well.

2 Many things are disrupted, but I can still manage.

$3 \quad$ My life is disrupted in many ways and I have trouble managing. 
$4 \quad$ My life is completely disrupted and I cannot function at all.

5. How difficult is it for you to disregard thoughts about the lack of symmetry and order, and refrain from urges to arrange things in order or repeat certain behaviors when you try to do so? $0 \quad$ Not at all difficult

$1 \quad$ A little difficult

2 Moderately difficult

$3 \quad$ Very difficult

4 Extremely difficult 


\section{Appendix C}

\section{Monetary Choice Questionnaire 21 (MCQ-21)}

For each of the next 21 choices, please indicate which reward you would prefer: the smaller reward today, or the larger reward in the specified number of days.

Although you will not actually receive any of the money, pretend that you will actually be receiving the amount that you indicate. Therefore, please answer each question honestly and as if you will actually receive the amount chosen either today or after a specified number of days.

To indicate your choice, please indicate the amount and time as shown in following example:

0 . Would you prefer $\$ 100$ today, or $\$ 100$ in 45 days?

1. Would you prefer $\$ 30$ today, or $\$ 85$ in 14 days?

2. Would you prefer $\$ 40$ today, or $\$ 55$ in 25 days?

3. Would you prefer $\$ 67$ today, or $\$ 85$ in 35 days?

4. Would you prefer $\$ 34$ today, or $\$ 35$ in 43 days?

5. Would you prefer $\$ 15$ today, or $\$ 35$ in 10 days?

6 . Would you prefer $\$ 32$ today, or $\$ 55$ in 20 days?

7. Would you prefer $\$ 83$ today, or $\$ 85$ in 35 days?

8. Would you prefer $\$ 21$ today, or $\$ 30$ in 75 days?

9. Would you prefer $\$ 48$ today, or $\$ 55$ in 45 days?

10. Would you prefer $\$ 40$ today, or $\$ 65$ in 70 days?

11. Would you prefer $\$ 25$ today, or $\$ 35$ in 25 days?

12. Would you prefer $\$ 65$ today, or $\$ 75$ in 50 days?

13. Would you prefer $\$ 24$ today, or $\$ 55$ in 10 days?

14. Would you prefer $\$ 30$ today, or $\$ 35$ in 20 days?

15 . Would you prefer $\$ 53$ today, or $\$ 55$ in 55 days?

16. Would you prefer $\$ 47$ today, or $\$ 60$ in 50 days?

17. Would you prefer $\$ 40$ today, or $\$ 70$ in 20 days?

18. Would you prefer $\$ 50$ today, or $\$ 80$ in 70 days?

19. Would you prefer $\$ 45$ today, or $\$ 70$ in 35 days?

20 . Would you prefer $\$ 27$ today, or $\$ 30$ in 35 days?

21 . Would you prefer $\$ 16$ today, or $\$ 30$ in 35 days? 


\section{Appendix D}

The Mindful Attention Awareness Scale (MAAS) - State

Using the 0-6 scale shown, please indicate to what degree you were having each experience described below when you were paged. Please answer according to what really reflected your experience rather than what you think your experience should have been.

0 1

not at all
2

3

Somewhat
4

5 6

1. I was finding it difficult to stay focused on what was happening.

2. I was doing something without paying attention.

3. I was preoccupied with the future or the past.

4. I was doing something automatically, without being aware of what I was doing.

5. I was rushing through something without being really attentive to it. 


\section{Appendix E}

\section{Affect Questionnaire}

1. How positive are you feeling right now?

1

2

3

Not Very

2. How negative are you feeling right now?

1

2

3

4

Not Very
5

6

7

5

6

7

Very

Very 


\section{Appendix F}

Freiburg Mindfulness Inventory (FMI)

Please respond to each item by marking one choice.

\begin{tabular}{|c|c|c|c|c|}
\hline & Rarely & Occasionally & Fairly often & Almost always \\
\hline $\begin{array}{l}\text { 1. I am open to the experience } \\
\text { of the present moment. }\end{array}$ & 1 & 2 & 3 & 4 \\
\hline $\begin{array}{l}\text { 2. I sense my body, whether } \\
\text { eating, cooking, cleaning, or } \\
\text { talking. }\end{array}$ & 1 & 2 & 3 & 4 \\
\hline $\begin{array}{l}\text { 3. When I notice an absence of } \\
\text { mind, I gently return to the } \\
\text { experience of the here and } \\
\text { now. }\end{array}$ & 1 & 2 & 3 & 4 \\
\hline $\begin{array}{l}\text { 4. I am able to appreciate } \\
\text { myself. }\end{array}$ & 1 & 2 & 3 & 4 \\
\hline $\begin{array}{l}\text { 5. I pay attention to what's } \\
\text { behind my actions. }\end{array}$ & 1 & 2 & 3 & 4 \\
\hline $\begin{array}{l}\text { 6. I see my mistakes and } \\
\text { difficulties without judging } \\
\text { them. }\end{array}$ & 1 & 2 & 3 & 4 \\
\hline $\begin{array}{l}\text { 7. I feel connected to my } \\
\text { experience in the here-and- } \\
\text { now. }\end{array}$ & 1 & 2 & 3 & 4 \\
\hline $\begin{array}{l}\text { 8. I accept unpleasant } \\
\text { experiences. }\end{array}$ & 1 & 2 & 3 & 4 \\
\hline $\begin{array}{l}\text { 9. I am friendly to myself when } \\
\text { things go wrong. }\end{array}$ & 1 & 2 & 3 & 4 \\
\hline $\begin{array}{l}\text { 10. I watch my feelings without } \\
\text { getting lost in them. }\end{array}$ & 1 & 2 & 3 & 4 \\
\hline $\begin{array}{l}\text { 11. In difficult situations, I can } \\
\text { pause without immediately } \\
\text { reacting. }\end{array}$ & 1 & 2 & 3 & 4 \\
\hline $\begin{array}{l}\text { 12. I experience moments of } \\
\text { inner peace and ease, even } \\
\text { when things get hectic and } \\
\text { stressful. }\end{array}$ & 1 & 2 & 3 & 4 \\
\hline
\end{tabular}


13. I am impatient with myself $\quad 1$ and with others. (R)

14. I am able to smile when I notice how I sometimes make life difficult.
2

3

4

2

3

4 


\section{Appendix G}

\section{Barratt Impulsiveness Scale 11 (BIS-11)}

Directions: People differ in the ways they act and think in different situations. This is a test to measure some of the ways in which you act and think. Read each statement and select the answer that nest describes you. Do not spend too much time on any statement. Answer quickly and honestly.
1
Rarely/Never
Occasionally
3
Often

4

Almost

Always/Always

1 I plan tasks carefully.

2 I do things without thinking.

3 I make-up my mind quickly.

4 I am happy-go-lucky.

5 I don't "pay attention."

6 I have "racing" thoughts.

7 I plan trips well ahead of time.

8 I am self controlled.

9 I concentrate easily.

10 I save regularly.

11 I "squirm" at plays or lectures.

12 I am a careful thinker.

13 I plan for job security.

14 I say things without thinking.

15 I like to think about complex problems.

16 I change jobs.

17 I act "on impulse."

18 I get easily bored when solving thought problems.

19 I act on the spur of the moment.

20 I am a steady thinker.

21 I change residences.

22 I buy things on impulse.

23 I can only think about one thing at a time.

24 I change hobbies.

25 I spend or charge more than I earn.

26 I often have extraneous thoughts when thinking.

$\begin{array}{llll}1 & 2 & 3 & 4 \\ 1 & 2 & 3 & 4 \\ 1 & 2 & 3 & 4 \\ 1 & 2 & 3 & 4 \\ 1 & 2 & 3 & 4 \\ 1 & 2 & 3 & 4 \\ 1 & 2 & 3 & 4 \\ 1 & 2 & 3 & 4 \\ 1 & 2 & 3 & 4 \\ 1 & 2 & 3 & 4 \\ 1 & 2 & 3 & 4 \\ 1 & 2 & 3 & 4 \\ 1 & 2 & 3 & 4 \\ 1 & 2 & 3 & 4 \\ 1 & 2 & 3 & 4 \\ 1 & 2 & 3 & 4 \\ 1 & 2 & 3 & 4 \\ 1 & 2 & 3 & 4 \\ 1 & 2 & 3 & 4 \\ 1 & 2 & 3 & 4 \\ 1 & 2 & 3 & 4 \\ 1 & 2 & 3 & 4 \\ 1 & 2 & 3 & 4 \\ 1 & 2 & 3 & 4 \\ 1 & 2 & 3 & 4 \\ 1 & 2 & 3 & 4\end{array}$


27 I am more interested in the present than the future.

$28 \mathrm{I}$ am restless at the theater or lectures.

$\begin{array}{llll}1 & 2 & 3 & 4 \\ 1 & 2 & 3 & 4 \\ 1 & 2 & 3 & 4 \\ 1 & 2 & 3 & 4\end{array}$

30 I am future oriented. 


\section{Appendix H}

\section{Depression Anxiety Stress Scale Short Form (DASS-21)}

Please read each statement and circle a number $0,1,2$ or 3 which indicates how much the statement applied to you over the past week. There are no right or wrong answers. Do not spend too much time on any statement.

The rating scale is as follows:

$0 \quad$ Did not apply to me at all

$1 \quad$ Applied to me to some degree, or some of the time

2 Applied to me to a considerable degree or a good part of time

3 Applied to me very much or most of the time

1 (s) I found it hard to wind down

2 (a) I was aware of dryness of my mouth

3 (d) I couldn't seem to experience any positive feeling at all

$\begin{array}{llll}0 & 1 & 2 & 3 \\ 0 & 1 & 2 & 3 \\ 0 & 1 & 2 & 3\end{array}$

4 (a) I experienced breathing difficulty (e.g. excessively rapid

$\begin{array}{llll}0 & 1 & 2 & 3\end{array}$
breathing, breathlessness in the absence of physical exertion)

5 (d) I found it difficult to work up the initiative to do things $\quad \begin{array}{llllll}0 & 1 & 2 & 3\end{array}$

6 (s) I tended to over-react to situations $\quad \begin{array}{lllll}0 & 1 & 2 & 3\end{array}$

7 (a) I experienced trembling (e.g. in the hands) $\quad \begin{array}{llll}0 & 1 & 2 & 3\end{array}$

8 (s) I felt that I was using a lot of nervous energy $\quad \begin{array}{llll}0 & 1 & 2 & 3\end{array}$

9 (a) I was worried about situations in which I might panic and $\quad \begin{array}{lllll}0 & 1 & 2 & 3\end{array}$ make a fool of myself

10 (d) I felt that I had nothing to look forward to $\quad \begin{array}{llll}0 & 1 & 2 & 3\end{array}$

11 (s) I found myself getting agitated $\quad \begin{array}{llll}0 & 1 & 2 & 3\end{array}$

12 (s) I found it difficult to relax $\quad \begin{array}{lllll}0 & 1 & 2 & 3\end{array}$

13 (d) I felt down-hearted and blue $\quad \begin{array}{llll}0 & 1 & 2 & 3\end{array}$

14 (s) I was intolerant of anything that kept me from getting on with $\quad \begin{array}{llll}0 & 1 & 2 & 3\end{array}$ what I was doing

15 (a) I felt I was close to panic $\quad \begin{array}{lllll}0 & 1 & 2 & 3\end{array}$

16 (d) I was unable to become enthusiastic about anything $\quad \begin{array}{lllll}0 & 1 & 2 & 3\end{array}$

17 (d) I felt I wasn't worth much as a person $\quad \begin{array}{llll}0 & 1 & 2 & 3\end{array}$

18 (s) I felt that I was rather touchy $\quad \begin{array}{llll}0 & 1 & 2 & 3\end{array}$ 
19 (a) I was aware of the action of my heart in the absence of physical exertion (e.g. sense of heart rate increase, heart missing a beat)

20 (a) I felt scared without any good reason

$\begin{array}{llll}0 & 1 & 2 & 3\end{array}$

21 (d) I felt that life was meaningless

$\begin{array}{llll}0 & 1 & 2 & 3\end{array}$




\section{Appendix I}

\section{Consideration of Future Consequences Scale (CFCS)}

For each of the statements below, please indicate whether or not the statement is characteristic of you. If the statement is extremely uncharacteristic of you (not at all like you) please fill-in a "1"; if the statement is extremely characteristic of you (very much like you) please fill-in a "5". Use the numbers in the middle if you fall between the endpoints. Please keep the following scale in mind as you rate each of the statements below.

$1=$ extremely uncharacteristic

$2=$ somewhat uncharacteristic

$3=$ uncertain

$4=$ somewhat characteristic

$5=$ extremely characteristic

1. I consider how things might be in the future, and try to influence those things with my day to day behavior.

2. Often I engage in a particular behavior in order to achieve outcomes that may not result for many years.

3. I only act to satisfy immediate concerns, figuring the future will take care ofitself.

4. My behavior is only influenced by the immediate (i.e., a matter of days or weeks) outcomes of my actions.

5. My convenience is a big factor in the decisions I make or the actions Itake.

6. I am willing to sacrifice my immediate happiness or well-being in order to achieve future outcomes.

7. I think it is important to take warnings about negative outcomes seriously even if the negative outcome will not occur for many years.

8. I think it is more important to perform a behavior with important distant consequences than a behavior with less-important immediate consequences.

9. I generally ignore warnings about possible future problems because I think the problems will be resolved before they reach crisis level.

10. I think that sacrificing now is usually unnecessary since future outcomes can be dealt with at a later time.

11. I only act to satisfy immediate concerns, figuring that I will take care of future problems that may occur at a later date.

12. Since my day to day work has specific outcomes, it is more important to me than behavior that has distant outcomes. 


\section{Appendix J}

\section{Demographics Questionnaire}

1. Please indicate your age.

2. Although the categories listed below may not represent your full identity or use the language you prefer, for the purpose of this survey, please indicate which group below most accurately describes your racial identification? (check all that apply)

-Native American/American Indian/Alaska Native/Indigenous

-Black

-Asian

-Latinx/Hispanic (Non-White)

-Middle Eastern/North African (Non-White)

-Pacific Islander/Native Hawaiian

-White

-Other

3. What is your ethnicity?

-Hispanic/Latino

-Not Hispanic/Latino

-I prefer not to answer

4. What is your gender identity?

-Male

-Female

-Transgender

-Nonbinary/fluid queer/gender queer

-Other

5. What is your approximate yearly household income in US dollars?

-Less than $\$ 10,000$

$-\$ 10,000$ to $\$ 19,999$

$-\$ 20,000$ to $\$ 29,999$

$-\$ 30,000$ to $\$ 39,999$

$-\$ 40,000$ to $\$ 49,999$

$-\$ 50,000$ to $\$ 59,999$

$-\$ 60,000$ to $\$ 69,999$

$-\$ 70,000$ to $\$ 79,999$

$-\$ 80,000$ to $\$ 89,999$

$-\$ 90,000$ to $\$ 99,999$

$-\$ 100,000$ to $\$ 149,999$

$-\$ 150,000$ or more

6. Please indicate your highest educational attainment.

-Elementary School 


\author{
-Junior High \\ -Some High School \\ -High School Graduate \\ -Some College \\ -Associate's Degree \\ -Bachelor's Degree \\ -Some Graduate School \\ -Graduate School Degree
}

7. What is your marital status?

-Single

-Single, but casually dating

-Single, but currently engaged to be married

-Single, but currently living with someone in a marriage-like relationship

-Married

-In a domestic or civil union

-Separated

-Divorced

-Widow/widower

-Other

8. What is your household annual income (before taxes and other deductions)? 


\section{Appendix K}

Mindfulness Induction Script - 9 minutes

Note: Speak calmly and lightly. Include pauses; speak in a way that encourages a sense of slowing down and taking space.

The first task that we will have you do today is an exercise designed to help you become more fully aware of what is happening in the moment. It is important for this study that you participate fully in this exercise by genuinely following the instructions.

Find a comfortable position in your chair with your feet flat on the floor and your back straight but not stiff or straining. Resting your hands on the top of your thighs. Finding a position that is alert while relaxed. Closing your eyes if that feels comfortable.

We're going to use your breathing to anchor your attention in your present experience, by noticing the qualities of each breath as it unfolds. <little pause> Start by bringing your attention to your belly and chest - wherever you feel your breath moving in your torso - feel this area rise or expand gently as you breathe in, and then feel it fall or draw back as you breathe out. Then continue to observe the feelings of each breath in and out, without trying to control your breathing if you can. The point is to be aware of your breathing, something we usually do without much awareness, feeling how it feels as it flows in and flows out.

<pause for initial practice time -15 seconds $>$

Your mind is likely to wander away from your breathing at some point. This is normal and there's no need to judge it. Just notice and accept wherever your mind is, with a sense of curiosity. Note your momentary thoughts as thoughts, and passing feelings as feelings. This returns you to noticing your current experience. Then, you can gently shift your attention back to your anchor: the feeling of each breath coming in and going out. Continue with this process of observing the feeling of your breathing.

<pause -45 seconds $>$

This technique is all you need to do during this exercise. If you happen to think this is foolish or boring, let those momentary thoughts be and then gently return to the process of noticing each breath in each moment.

Now, you will be given some quiet time to continue with this exercise. Every now and then during this quiet time, you will hear some reminders. Please continue to attend to the feelings of each breath in and out.

<pause/quiet time begins> 
Reminders:

Gently maintain attention on your breathing, being with each breath in for its full duration and each breath out for its full duration.

If your mind wanders, acknowledge that it has wandered to reconnect to the present, and gently shift your attention back to noticing the feeling of each breath.

Let yourself become more familiar with the process of this experience.

Keep it really simple.

End: This exercise is now over. Slowly open your eyes if they are closed, and take a moment if you need one. Then, turn the computer monitor back on and click continue. 


\section{Appendix L}

Thought Wandering /Unfocused Attention Script - 9 minutes

The first task that we will have you do today is an exercise designed to encourage you to perceive things in a way that lets your mind wander freely. It is important for this study that you participate fully in this exercise by genuinely following the instructions.

Find a comfortable position in your chair with your feet flat on the floor and your back straight but not stiff or straining. Rest your hands on the top of your thighs. Find a position that is alert while relaxed. Close your eyes if that feels comfortable.

We're going to ask you to think about whatever comes to mind, without having to focus on anything in particular. <little pause> Take this time to follow your thoughts and feelings whatever you want to think about - as you do when you have time to think things through thoroughly. For example, sometimes we think about ideas for later in the day or week to organize our plans. Or, sometimes we think about something that happened earlier in our day. You may have a lot to think about, maybe important things, or your mind might just wander to anything. Either way, take time to think about whatever you want. Just let your mind think and wander freely.

<pause for 15 seconds>

We are simply giving you time to let your mind wander freely through all your thoughts. Sometimes we don't have time to let our minds wander or think through everything with all that goes on. Yet everybody has their own interests, concerns and ideas that occupy their thoughts when they have time. Sometimes we want some time just to think. So, during this time, you can let your mind go wherever it wants as time passes. Continue to let yourself think about whatever you want to.

<pause -45 seconds>

That is all you need to do during this exercise. It's that simple. Use the time to let your mind wander and think freely without needing to focus hard on anything in particular. Even if you zone out a bit, that's okay. Now, you will be given some quiet time to continue with this exercise. Every now and then during this quiet time, you will hear some reminders. Please continue to let your mind wander and think freely during this time.

<pause/quiet time begins>

Reminders:

Remember: this is time for your mind to wander freely.

As a reminder, you don't have or even want to think about one thing; think about as many different things as you want. 
Don't focus too hard on anything. Think freely.

The exercise is simple.

End: This exercise is now over. Slowly open your eyes if they are closed, and take a moment if you need one. Then, turn the computer monitor back on and click continue. 


\section{Appendix M}

\section{Handwashing Delay Discounting Task (HDDT)}

\section{Handwashing Delay Discounting Task Instructions}

After using a public restroom, you are about to leave and as you grab the door handle to exit, you notice a sticky, gooey substance on the handle and is now on your hand. On the floor next to the door, you see a used and discarded tissue with the same mucus-like substance that is now on your hand. This substance is not seriously harmful to your health and has no adverse consequences other than the unpleasantness normally associated with another person's mucus on your hand. Before you are able to remove this substance imagine you are presented with the following choices.

Choices Presented to Participants in the Handwashing Delay-Discounting Task

\begin{tabular}{lll}
\hline $\begin{array}{l}\text { Immediate Handwashing and } \\
\text { Amount (dollars) }\end{array}$ & Delayed Amount (dollars) & $\begin{array}{l}\text { Delay to Handwashing } \\
\text { (number of minutes) }\end{array}$ \\
\hline 27 & 30 & 44 \\
30 & 35 & 41 \\
19 & 25 & 2 \\
17 & 25 & 48 \\
10 & 35 & 25 \\
13 & 25 & 58 \\
11 & 35 & 35 \\
24 & 25 & 173 \\
33 & 35 & 61 \\
34 & 35 & 47 \\
20 & 30 & 126 \\
13 & 25 & 37 \\
18 & 30 & 106 \\
21 & 25 & 30 \\
12 & 35 & 12 \\
20 & 25 & 158 \\
28 & 30 & 113 \\
16 & 25 & 14 \\
14 & 35 & 6 \\
29 & 30 & 130 \\
19 & 25 & 5 \\
18 & 25 & 98 \\
26 & 35 & 22 \\
11 & 30 & 109 \\
\hline
\end{tabular}




\begin{tabular}{lll}
\hline 17 & 35 & 168 \\
34 & 35 & 110 \\
15 & 30 & 4 \\
28 & 30 & 45 \\
12 & 25 & 11 \\
33 & 35 & 152 \\
23 & 30 & 3 \\
15 & 30 & 16 \\
29 & 30 & 87 \\
16 & 35 & 119 \\
29 & 30 & 170 \\
26 & 30 & 15 \\
13 & 35 & 43 \\
31 & 35 & 81 \\
24 & 25 & 112 \\
10 & 35 & 99 \\
27 & 30 & 111 \\
25 & 30 & 8 \\
20 & 25 & 1 \\
14 & 30 & 7 \\
34 & 35 & 160 \\
21 & 25 & 76 \\
22 & 30 & 9 \\
22 & 25 & 136 \\
23 & 25 & 145 \\
25 & 35 & 159 \\
24 & 25 & 180 \\
\hline & & \\
\hline
\end{tabular}




\section{Appendix N}

\section{Monetary Choice Questionnaire-27 (MCQ-27)}

For each of the next 27 choices, please indicate which reward you would prefer: the smaller reward today, or the larger reward in the specified number of days.

Although you will not actually receive any of the money, pretend that you will actually be receiving the amount that you indicate. Therefore, please answer each question honestly and as if you will actually receive the amount chosen either tonight or after a specified number of days.

1. Would you prefer $\$ 54$ today, or $\$ 55$ in 117 days?

2. Would you prefer $\$ 55$ today, or $\$ 75$ in 61 days?

3. Would you prefer $\$ 19$ today, or $\$ 25$ in 53 days?

4. Would you prefer $\$ 31$ today, or $\$ 85$ in 7 days?

5 . Would you prefer $\$ 14$ today, or $\$ 25$ in 19 days?

6. Would you prefer $\$ 47$ today, or $\$ 50$ in 160 days?

7. Would you prefer $\$ 15$ today, or $\$ 35$ in 13 days?

8 . Would you prefer $\$ 25$ today, or $\$ 60$ in 14 days?

9. Would you prefer $\$ 78$ today, or $\$ 80$ in 162 days?

10 . Would you prefer $\$ 40$ today, or $\$ 55$ in 62 days?

11. Would you prefer $\$ 11$ today, or $\$ 30$ in 7 days?

12. Would you prefer $\$ 67$ today, or $\$ 75$ in 119 days?

13. Would you prefer $\$ 34$ today, or $\$ 35$ in 186 days?

14. Would you prefer $\$ 27$ today, or $\$ 50$ in 21 days?

15 . Would you prefer $\$ 69$ today, or $\$ 85$ in 91 days?

16. Would you prefer $\$ 49$ today, or $\$ 60$ in 89 days?

17. Would you prefer $\$ 80$ today, or $\$ 85$ in 157 days?

18 . Would you prefer $\$ 24$ today, or $\$ 35$ in 29 days?

19 . Would you prefer $\$ 33$ today, or $\$ 80$ in 14 days?

20. Would you prefer $\$ 28$ today, or $\$ 30$ in 179 days?

21 . Would you prefer $\$ 34$ today, or $\$ 50$ in 30 days?

22 . Would you prefer $\$ 25$ today, or $\$ 30$ in 80 days?

23 . Would you prefer $\$ 41$ today, or $\$ 75$ in 20 days?

24 . Would you prefer $\$ 54$ today, or $\$ 60$ in 111 days?

25 . Would you prefer $\$ 54$ today, or $\$ 80$ in 30 days?

26 . Would you prefer $\$ 22$ today, or $\$ 25$ in 136 days?

27 . Would you prefer $\$ 20$ today, or $\$ 55$ in 7 days? 